CONSUMER PURCHASE DECISIONS REGARDING SCREW CAP WINES

\author{
A Thesis \\ presented to \\ the Faculty of California Polytechnic State University, \\ San Luis Obispo
}

In Partial Fulfillment

of the Requirements for the Degree

Master of Science in Agribusiness

By

Lauren Michelle Jeter

November 2012 
(C) 2012

Lauren Michelle Jeter

ALL RIGHTS RESERVED 
COMMITTEE MEMBERSHIP

TITLE:

Consumer purchase decisions regarding screw cap wines

AUTHOR: $\quad$ Lauren Michelle Jeter

DATE SUBMITTED: November 2012

COMMITTE CHAIR: $\quad$ William H. Amspacher, Ph.D.

COMMITTEE MEMBER: $\quad$ Stacey L. Rucas, Ph.D.

COMMITTEE MEMBER: $\quad$ Gerry Ritchie, Ph.D 


\title{
ABSTRACT \\ Consumer Purchase decisions regarding screw cap wines
}

\author{
Lauren Michelle Jeter
}

Screw cap wine closures provide many benefits in maintenance of wine quality over time, however acceptance of their use by purchasers has varied. This work first investigates how factors like age, gender, income and education affect the decision to purchase screw cap wines and to what extent these factors impact consumer decisions to bring screw cap wine to various social settings. The results of a questionnaire pooling attitudes and behaviors of wine purchasers $(n=319)$ indicate that factors such as age, wine knowledge, income and gender influence a consumer's decision to purchase screw cap wine. Education and income positively impact the acceptance of screw cap wines and the likelihood of purchasing them. Age has a negative effect on acceptance of screw cap wines in social situations. Gender was found to not be significant in regards to likelihood of screw cap wine purchase generally, however men tended to view screw cap wines as more acceptable in more social situations than women.

Keywords: Consumer perceptions, social appropriateness, wine, screw caps, wine closure type, consumer behavior, wine marketing 
TABLE OF CONTENTS

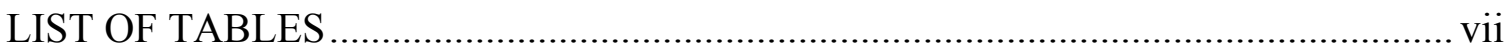

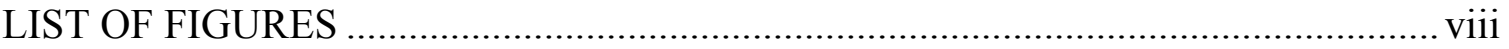

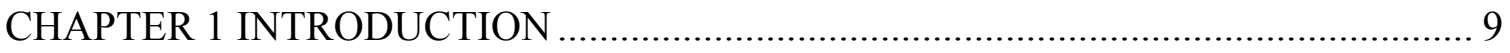

Introduction

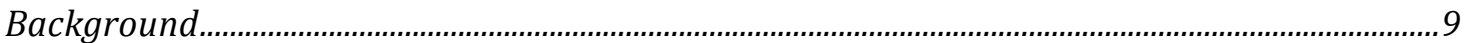

Purpose of Study

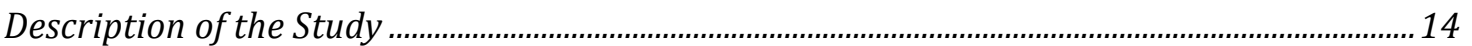

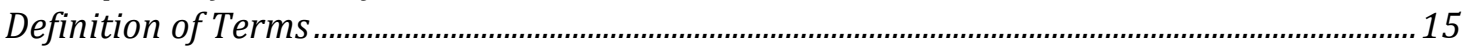

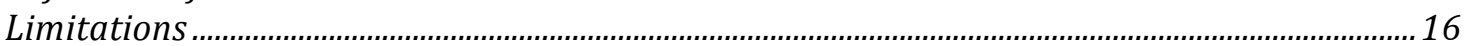

Summary

CHAPTER 2 REVIEW OF LITERATURE .............................................................. 18

Introduction

Closure Types.................................................

Global Acceptance

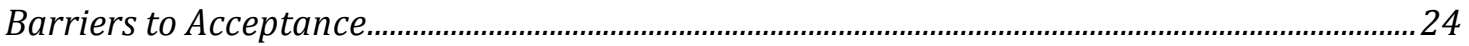

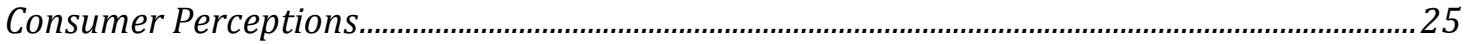

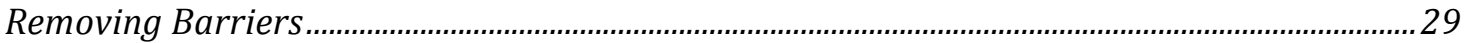

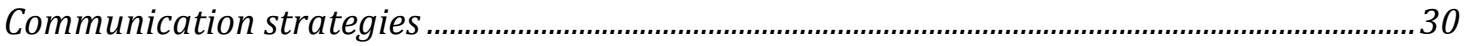

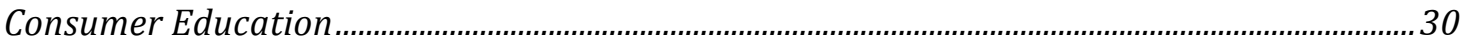

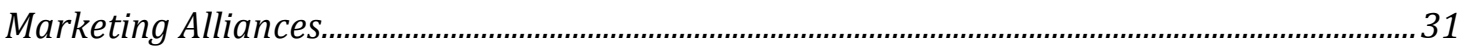

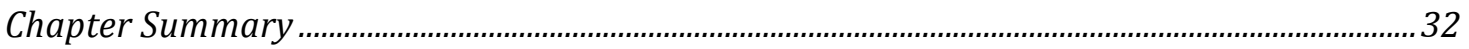

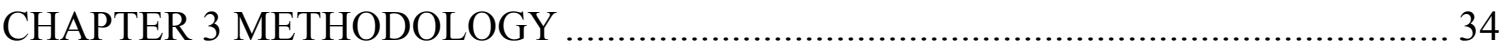

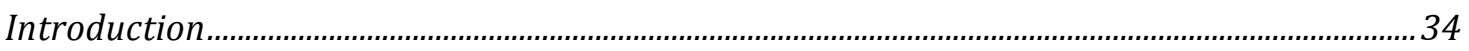

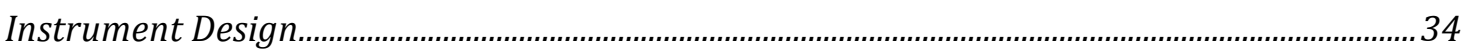

Pilot Study

Sample

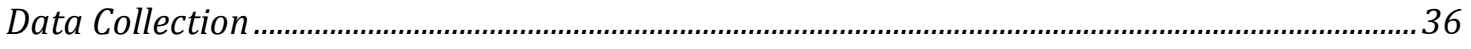

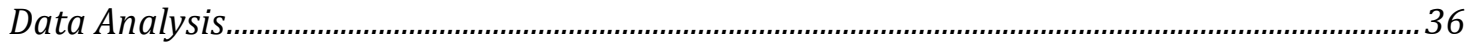

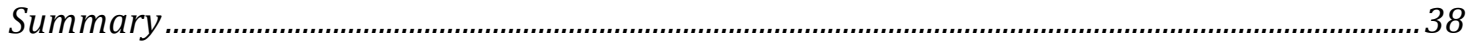

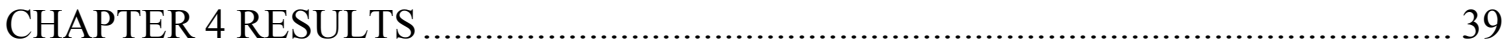

Sample Statistics

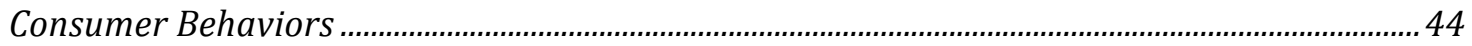

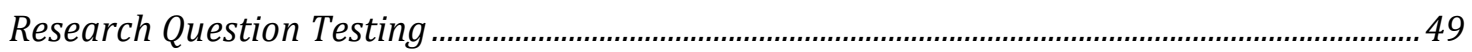

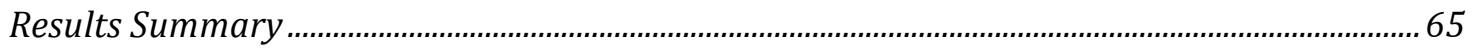

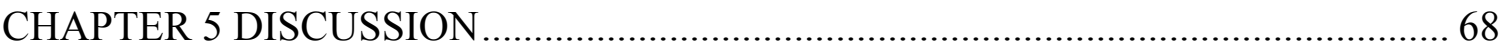

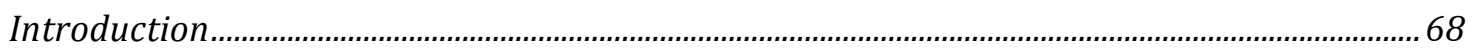

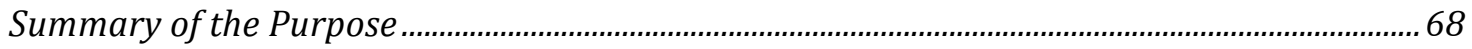

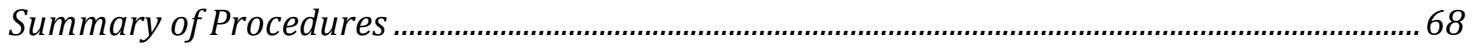

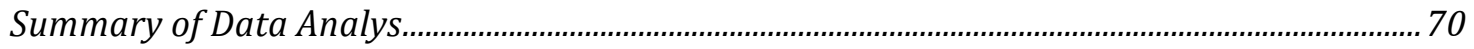

Delimitations

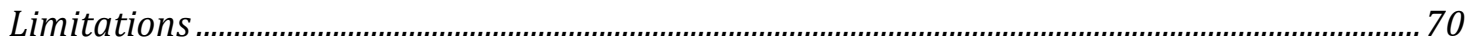

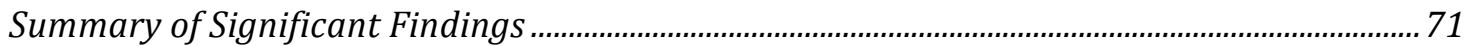

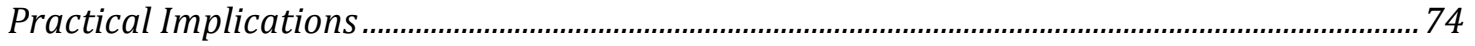


Recommendation for future research ... 


\section{LIST OF TABLES}

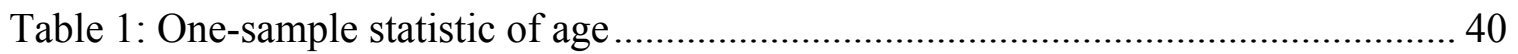

Table 2: Demographic Variable Summary ……………................................................. 44

Table 3: Agreement statements for closure method …………....................................... 48

Table 4: Results of Chi-square Analysis of Decision to Purchase Screw Cap Wine by

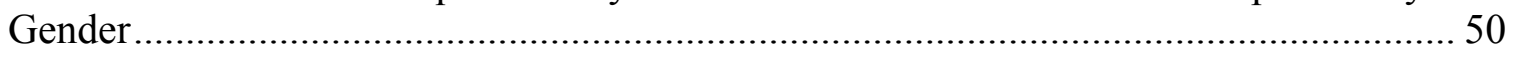

Table 5: Individual Model Results: Decision to Purchase Screw Cap Wine..................... 51

Table 6: Results Decision to Purchase Screw Cap Wine................................................. 52

Table 7: Summary of Screw Cap Wine Bottles Purchased Last Month ............................ 54

Table 8: Gender Differences in Number of Screw Cap Wine Bottles Purchased Last

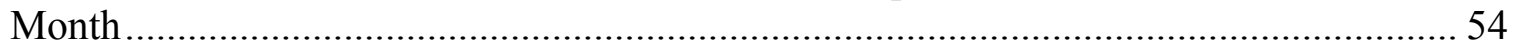

Table 9: Results Number of Screw Cap Wine Bottles Purchased Last Month................. 55

Table 10: Results of GLM on Social Inappropriateness of Closure Type in Different

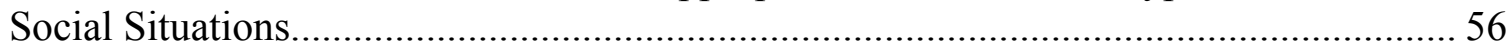

Table 11:Results Likelihood to Bring Screw Cap Wine to Boss Party ............................ 60

Table 12: Results Likelihood to Bring Screw Cap Wine to Dinner with Close Friends .. 61

Table 13: Results Likelihood to Bring Screw Cap Wine to Christmas Party .................... 62

Table 14:Results Likelihood to Bring Screw Cap Wine to Thanksgiving Dinner ............ 62

Table 15:Results Likelihood to Bring Screw Cap Wine to a Superbowl Party ................. 64

Table 16:Results Likelihood to Bring Screw Cap Wine as a Gift for a Friend ................ 65 


\section{LIST OF FIGURES}

Figure 1: Wine closures: screw cap, synthetic cork, technical corks and natural cork..... 21

Figure 2: Rising screw cap usage in Australia (Speedy, 2010) ................................... 23

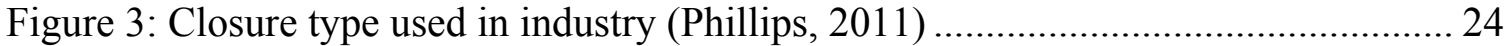

Figure 4: Consumer acceptance of screw cap wines over time (Bleibaum, 2011) .......... 27

Figure 5: Appropriateness of closures by usage situation (Bleibaum, 2011) .................. 28

Figure 7: Highest level of education ....................................................................... 41

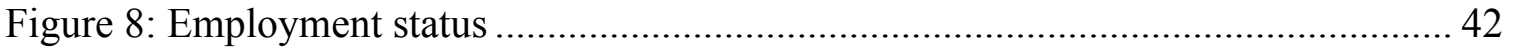

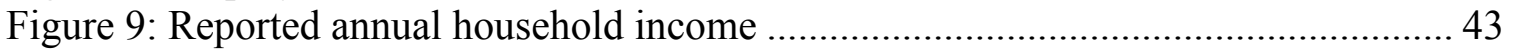

Figure 10: Percent of alcoholic beverages consumed last year by respondent................ 45

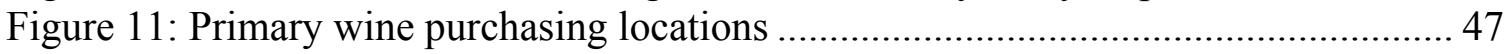

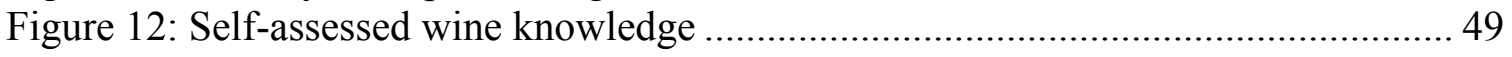

Figure 13: Social acceptability of Closure Type within Social Situation ........................ 59 


\section{CHAPTER 1 INTRODUCTION}

\section{Introduction}

While researching the topic of consumer attitudes towards screw caps, one question seemed to reoccur throughout the literature and data: if the international wine industry has proven screw cap closure methods to be superior in eliminating cork taint and wine spoilage, why do wine consumers in the United States continue to perceive screw cap closures as being low quality? Screw cap wine closures provide quality by safeguarding against spoilage and maintaining a cork-taint free product. The disconnect between industry knowledge and consumer understanding provides ground for the following research: what determines the variation in wine purchases and attitudes regarding various closure methods. The study predicted that income and wine knowledge could nudge consumers to purchase more screw cap wines and additionally education might increase the acceptance of screw cap closures by social situation.

\section{Background}

Closure types have significant impact on purchase decisions because they indicate quality. A study by Barber et al, shows that while screw cap closures prevent cork taint, crumbling cork and leakage, consumers perceive them as reflecting a poor brand image (Barber, 2007). The fact that screw cap closures eliminate cork taint contamination lead many wine experts to believe it is superior to other closure options in sustaining wine quality (Longo, 2005). "[The Industry] is taking the worst closure for the best wine and the best closure for the worst wine. There's so much of an emotional block. They'd rather 
be emotional about it than make money off it," weighed in Periscope Cellars owner and winemaker, Brendan Eliason, in an online Wine Business Monthly article (Tinney, 2007).

Nearly 50\% of consumers polled in 2007 believed screw cap wines were low quality wines (Bleibaum, 2011). According to a survey conducted in March 2004, only $30-55 \%$ of respondents believed that alternative closures could prevent wine spoilage or cork taint (Marin, Jorgensen, Kennedy, \& Ferrier, 2007). In one study, consumers were found to have negative purchase intent when considering screw cap wines (Marin \& Durham, 2007). This negative consumer intent was based mostly on quality assessments and perceptions of the consumer.

Screw cap wine closures are resistant innovations. Unlike receptive innovation welcomed by customers, resistant innovation may conflict with customers' belief structure or require large behavioral changes from what customers may perceive as acceptable. Resistant innovations, like screw cap closures, hold barriers from market acceptance such as value, risk, tradition and image barriers (Atkin, Garcia, \& Lockshin, 2006). There currently are value and image barriers that affect consumer perceptions that need attention. But what is not known exactly is the cause of the risk perceptions when buyers purchase screw cap wines. This risk is pervasive among buyers and is preventing, to some extent, the spread of screw cap adoption.

The motivational factors of gender, income and age on selecting a bottle of wine study shows $66 \%$ of respondents view screw cap closures indicative of cheap wine 
(Barber, Almanza, \& Donovan, 2006). This exemplifies how socio-economic factors influence wine selection. Wine is utilized not only as a beverage, but also as an index of cultural and financial exclusivity (Ritchie, 2007). If the consumer perception points to screw cap wines as cheap or inexpensive, then such a selection would reflect poorly on the consumer's taste in wine. This may deter future purchasing of screw caps. Ninety percent of US consumers, polled in a study, would not give a friend of the family a screw cap wine as a gift (Bleibaum, Lattey, \& Francis, 2005). Perceived disapproval by family and friends presents a social cost preventing the gifting, and hence purchasing, of screw cap wines.

Some countries have enjoyed higher acceptance rates and market shares for screw cap wines than others. Australia and New Zealand wineries bottle $40 \%$ and $80 \%$ respectively, of all wine produced with screw cap closures (Choi, Garcia, \& Friedrich, 2010). This compares to $5-10 \%$ of wines produces with screw cap closures in the United States. Brendan Eliason states "You have two countries [Australia and New Zealand] that have embraced screw cap over the past few decades and they are clobbering us on the market. It's tough to argue with the fact that the people who use screw caps [around the world] are the ones that are succeeding here," (Tinney, 2007). Successful marketing campaigns, such as Australia's "Rieslings with a Twist" and New Zealand's Wine Seal Initiative can be attributed to diffusion success, or how quickly a culture adopts a new idea or technology such as screw cap wine closure (Garcia, Rummel, \& Hauser, 2007). Both these campaigns focused on a common goal: emphasizing quality to wine trade, media, consumers and retailers collectively. 
Consumer education is a critical step in adoption of screw caps in the US market so that the perceived social costs in the minds of consumers and purchasers can be eliminated. Education should effectively be delivered with a unified message conveying how screw caps drastically eliminate cork taint for consumer consumption and consistently keeps wine as the winemaker intended. Not all consumers have a knowledge of cork taint but a corked bottle of wine can diminish a winery's brand even if the consumer doesn't know why it's bad. In regards to successful marketing campaigns of screw cap wines in the US, research shows that by sharing investment costs, collectively minimizing market risks, and pooling resources for marketing and screw cap manufacturing, the US wine industry could penetrate more available wine market shares (Garcia, Bardhi, \& Friedrich, 2011).

\section{Purpose of Study}

The purpose of this study is to find factors that influence screw cap wine purchase behaviors and to collect more information regarding social attitudes toward screw cap wine closures to aid the US wine industry in better understanding US wine consumer needs.

Although previous studies offer valuable information about consumer attitudes toward screw cap wines, they lack vital demographic data, are out of date, or survey too small a respondent pool. One problem, for example, with a major consumer perception study published in 2007 was that the data was collected in March 2004 . 
With updated consumer profile information, a marketing analysis could be better developed for a wine business focused on the screw cap wine market. There is also a lack of knowledge regarding willingness to purchase screw cap wines and to which social events consumers are more likely to bring screw cap wines. This data would enable wine marketers to focus on marketing campaigns catered to people willing to purchase screw cap wines and could allow more efficient penetration within a target market of screw cap wine drinkers. Many wine drinkers, for example, are not necessarily wine experts. As in many other human behaviors, people tend to follow expert trends when they lack specific experience and knowledge. Therefore, marketing programs might target changing consumer attitudes to view screw cap wines as superior and socially acceptable in more elite circles. This could prove useful for any winery looking focus their offerings of screw cap wine. This current study will contribute to the existing literature by finding factors that influence consumer perceived wine quality relative to closure type.

\section{Research Question}

1) What factors influence screw cap wine purchases?

a. Does age, gender, income, education, marital status, wine classes taken, amount spent on wine per month and wine knowledge affect the decision to purchase screw cap wines?

b. Do these same factors affect the number of bottles of screw cap wines purchased per month?

2) Does screw cap wine acceptance vary by social situation? 
a. Does acceptance of natural cork, artificial cork or screw cap closure depend on social situation?

b. Does acceptance of screw cap wines vary by specific social event (i.e. dinner at boss' house, Thanksgiving dinner, Superbowl)?

\section{Description of the Study}

An online survey was created to measure variation in perceived quality of method of wine closure. This survey was adapted from Effects of Wine Bottle Closure Type on Consumer Purchase Intent and Price Expectation (Marin et al., 2007) and Conjoint research for consumer perception of wine closure options and their impact on purchase interest in the United States and Australia (Bleibaum et al., 2005). A pilot study was conducted to improve the reliability of the survey instrument. This survey was made available for six weeks from February 2, 2009 - March 16, 2009 via web platforms including Facebook and Craigslist. The sample included 417 online respondents.

\section{Significance of the study}

Some of the proposed research questions posed in this study address many data gaps that exist in the wine industry. One such gap is lack of consumer purchase behavior data. One example of this would be anticipating if a consumer will bring screw cap wine to a particular social gathering like a Superbowl party. This could be useful in marketing and advertising campaigns. By better understanding what factors affect consumers purchasing decisions to buy screw cap wines, marketers can develop a clearer picture of whom they are marketing to. Insights gained from this study may contribute to more effective screw cap wine campaigns. 


\section{Definition of Terms}

This is a compiled glossary of terms used in this study.

1. Perceived quality by method of wine closure: value consumer derives by assessing wine solely based on closure method.

2. Coopition: when two or more industry firms, normally competing against each other form a strategic partnership to accomplish a specific goal.

3. Closure type: when evaluating the opening of a wine bottle, available options include natural cork, screw cap and artificial /alternative cork.

4. Natural cork: a traditional closure type for wine bottles, sources from cork tree.

5. Artificial cork: can be made of synthetic, plastic or composite cork material.

6. Screw cap closure: a metal cap with a top and bottom, threaded externally on wine bottle. Sometimes known as a Stelvin closure.

7. Wine knowledge: self-assessed intelligence regarding wine either gained formally or with wine consumption experience. 
8. Cork taint: 2,4,6-trichloroanisole (TCA) was discovered to be one of the primary compounds responsible for cork taint. Across the wine industry, cork taint is estimated to ruin $6-12 \%$ of all wine bottled with natural cork closures.

\section{Limitations}

This study has the following limitations:

1. Study was limited to those who responded to the online web survey.

2. Study was limited to respondents who use the web or email (99\% of which drank wine).

3. Study was limited to respondents in California only.

4. Study occurred in 2009 , thus data is not as current (or relevant) as desired.

\section{Ethical Considerations}

Cal Poly Human Subjects Committee review process was followed prior to launching study survey. Steven Davis, chair of Human Subjects Committee reviewed and approved study survey on May 8, 2008. The approval form, research protocol and sample consent form are attached to the study survey and can be found in the appendix.

Procedures were followed to ensure research was conducted in an ethical manner, including providing informed consent prior to participation, adequately protecting the privacy of subjects and confidentiality of data. Additionally, subjects were adequately debriefed regarding the purpose of the study. Subjects were offered means to contact the 
researcher including contact phone number and email address regarding results of the survey.

Summary

This study takes a look at consumer perceptions, buying behavior and consumer acceptance of wine closure types. It compares social acceptance of closure types by social situations. While there is marketing research data available regarding consumer purchase behavior, there is little data regarding consumer attitudes toward specific closure types. This study is important because it helps compile this information for the wine marketing industry. This new consumer attitude information can be used to further promote alternative closure type wines such as artificial cork and screw cap wines. 


\section{CHAPTER 2 REVIEW OF LITERATURE}

\section{Introduction}

Globally, screw cap closures have gained consumer acceptance in such countries as Australia, New Zealand and recently, the United Kingdom. At a national level, United States screw cap consumer acceptance seems to be lower than the global level. Within the U.S. wine industry, winemakers, wine producers and wine distributors seem hesitant to increase screw cap wine offerings to U.S. consumers, who don't view screw cap wine closures adding value to their wine purchases. If U.S. consumers drive screw cap wine offerings without the sway of global trends or industry research, what factors influence the quality of screw cap wines in the U.S.? Gaining knowledge of this information, the U.S. wine industry could better understand U.S. customers' needs. Additionally, it is important to understand why U.S. consumer behaviors toward screw cap wines show such great disparity from global consumer trends.

\section{Closure Types}

Cork is harvested from a tree called Quercus Suber or the common name, Spanish Cork Tree. The bark is harvested, seasoned, boiled, flattened, cut into strips, and punched in cork shapes. Corks are then inspected and some are further processed with paraffin, silicone material or stamped with branding. During processing, corks are treated to minimize growth microorganisms, primarily molds and yeasts (Gardner 2008). 
Cork taint cases undesirable smells or tastes in wine. Factors that contribute to cork taint could include storage conditions and the cork stopper used to close the wine. Two chemical agents are responsible: 2,4,6-trichloiroanisole and 2,4,6-tribromosnisole. When affected, wine can sometimes smell like moldy newspaper, wet dog or a damp basement (Gardner 2008).

The largest technical problem that natural corks present is cork taint. Faulty wine alienates consumers and degrades wine brand names. Retail facilities must replace faulty wine, and are thus financially liable. Consumers know little of this problem and certainly do not widely understand that alternative closures provide solutions to faulty wine (Wilson \& Lockshin, 2003).

Cork taint is a problem for both the customer as well as the winemaker. First of all, the novice wine drinker may not be able to identify a slightly cork tainted bottle and assume the taste is reflective of the quality of the wine along with the perceived quality of the winery itself. Additionally, a lower quality cork closure may shrink in size, thereby allowing an overabundance of air into the wine opening, causing oxidation, yielding vinegar like smells. In both scenarios, the wine is not truly being represented as the winemaker would like it to be .

Technical cork, similar to natural cork, is sourced from Quercus suber, or cork trees, then are ground up into small cork particles and glued together through a molding process. The production process includes washing the cork and sterilizing it to minimize 
potential TCA contamination. TCA is a main problem for both natural corks and technical corks (Phillips, 2011).

Synthetic corks are made from plastic materials that can either be produced by a polymer injection or via an extrusion mold. One general problem with synthetic corks is that they allow for more oxygen to leave the bottle, which can eventually oxidize the wine. One positive draw is that TCA or cork taint is not an issue using this closure method. Unfortunately, synthetics get stuck in the bottle and are difficult to extract with a corkscrew (Gardner, 2008).

One alternative to synthetic closures is the screw cap wine closure. A Screw cap is a metal enclosure that has a plastic lining. Screw caps can inhibit the flow of oxygen to the wine. Screw caps, also called "Stelvin" caps because of the manufacturing brand, reduce cork taint completely. In studies, screw cap closures retained fruit freshness and kept free sulfur dioxide more than any other closure (Goode, 2007). In the figure below, the reader can closely examine the difference between screw cap wine closures, synthetic corks, technical corks and natural cork wine closures. 


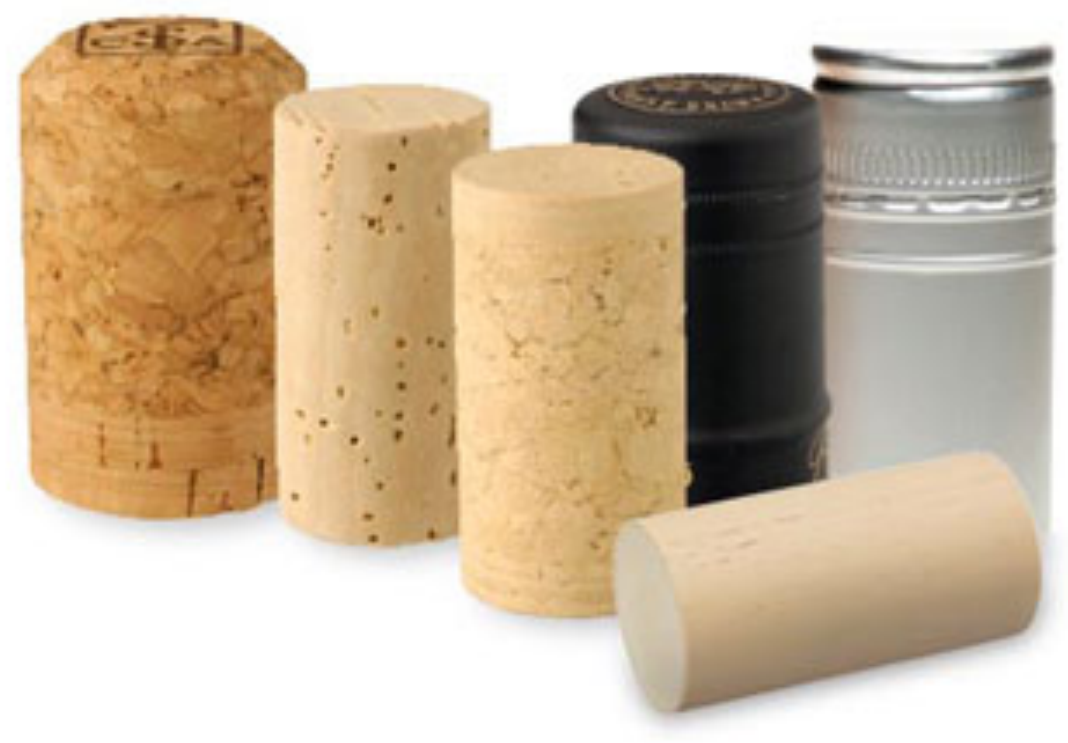

Figure 1: Wine closures: screw cap, synthetic cork, technical corks and natural cork

Not only do screw caps eliminate cork taint, they remove other cork issues such as crumbling and leaking out of the equation. An estimated $2-15 \%$ of all wine bottles using natural cork are damaged by cork taint (Choi et al., 2010). Cork taint costs the wine industry $\$ 10$ Billion a year and screw caps eliminate all cork taint (Charters \& Pettigrew, 2006). Ten billion dollars of wine wasted a year also has environmental implications. Screw cap wines closures prevent this waste, thus conserving water resources used to produce that amount of wine.

Screw cap closures were invented by Le Bouchage Mecanique in 1959. At the time, they were considered a breakthrough innovation as they eliminated the problem of oxidation and the risk of cork taint. Between 1976 and the early 1980's approximately 20 
million bottles were sealed with Stelvin closures. In the early 1980's, consumers rejected screw cap closures and wineries like Pewsey Vale (historically the largest winery distributing screw cap wine in Australia at the time) took major sales hits for providing their wines with screw caps. Pewsey Vale went back to cork closures, to save his wine's brand as a prestige product (Gardner, 2008).

During the 1970's the wine industry introduced screw cap closures to the market place as an alternative to faulty wine created by other closures. The product introduction was greeted with declining sales and poor quality perception, which contributed greatly to why this closure innovation has not successfully re-entered the market (Wilson \& Lockshin, 2003).

\section{Global Acceptance}

New Zealand wine industries produce between $70-80 \%$ of all wine with screw caps. Screw cap production in the US represented a mere $5 \%$ of the wine market (Garcia et al., 2011). Among Australian wines bottled for the domestic market the proportion of screw cap production is estimated at more than 90 per cent, with many cork-sealed wines intended for export markets such as the US. Australian wineries, such as Penfolds have used screw caps on all white wines since 2004 (Speedy, 2010). The graph below shows the gradual increase of screw cap acceptance in Australia from 2002-2010. 


\section{THE CORK SCREW}

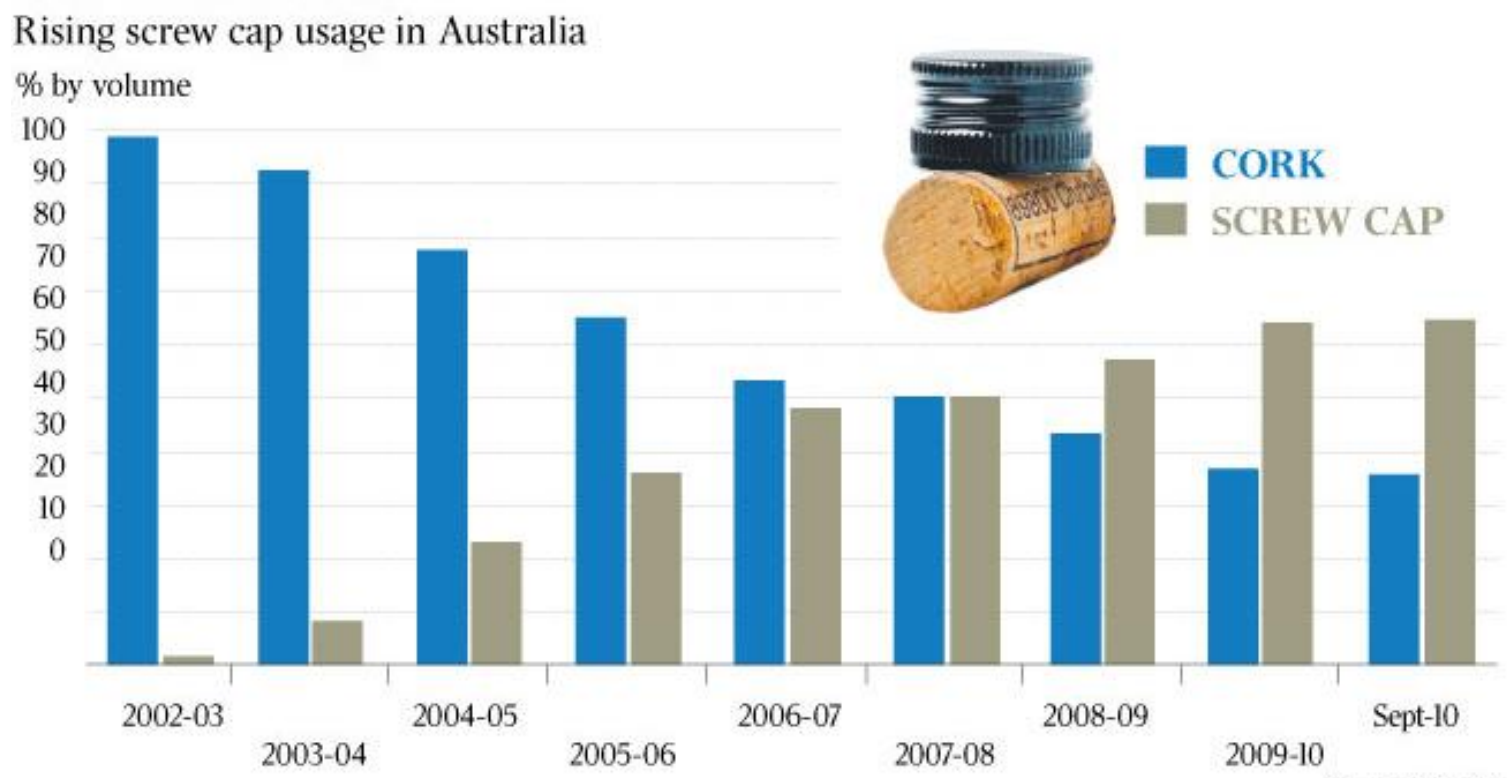

Figure 2: Rising screw cap usage in Australia (Speedy, 2010)

Usage of screw cap wines continues to be increasing in US industry use. This might have to do with consumer opinions improving regarding screw cap closures (Phillips, 2011). The graph shows the gradual increase of screw cap closures used in the US wine industry from 2004-2011. 


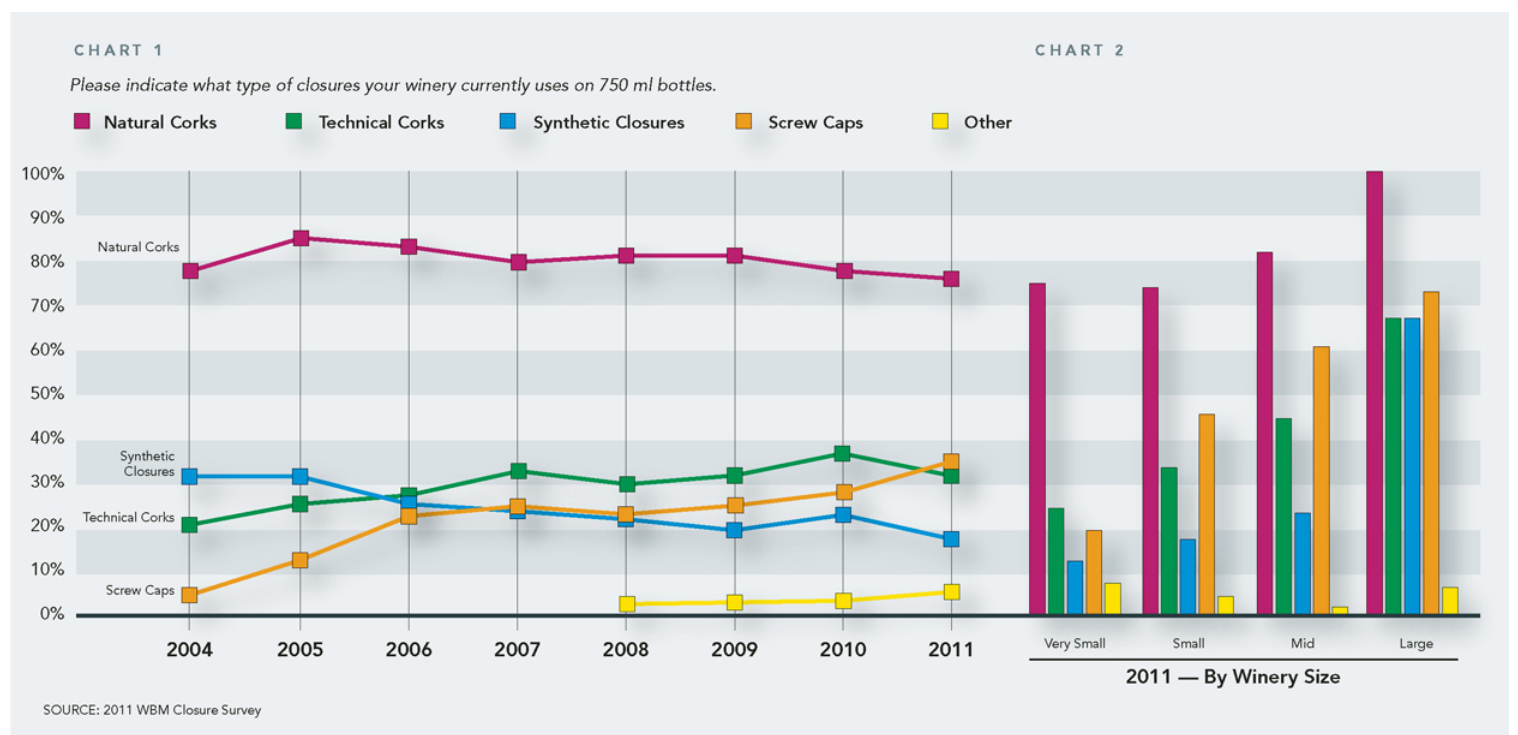

Figure 3: Closure type used in industry (Phillips, 2011)

\section{Barriers to Acceptance}

The historical association of screw caps has contributed to consumers associating screw cap wines as cheap. Risk barriers are evident when consumers hesitate to purchase screw cap wines due to social implications of the purchase (Choi et al., 2010).

Research has shown that cork is associated heavily with the long time tradition of wine drinking. Tradition barriers exist with screw cap wines because no such tradition exists. Image barriers for screw cap wines exist because when screw caps are mentioned, some consumers envision low-end "jug" wine (Choi et al., 2010). Based on this information, it's not hard to see why screw caps can be categorized as a resistant innovation. 
Negative consumer perceptions will be a large barrier to screw cap acceptance until marketers focus on conveying the message that screw caps are a reliable and consistent alternative to corks (Garcia et al., 2011).

Screw cap wine closures are resistant innovations or products that require consumers to change their behavior away from the status quo. Some aspects of resistance include barriers of acceptance, or factors that decrease the adoption and screw cap wines. Such barriers include value, risk, tradition and image barriers (Atkin et al., 2006). The wine industry has a screw cap product problem whereby the average consumer has perceived risks and uncertainties about the product. Cooperative, industry-wide marketing strategies signal consumers to prepare for serious permanent change in products, thus reducing consumer psychological switching costs. This will remove many consumer barriers to acceptance of screw caps (Garcia et al., 2011).

\section{Consumer Perceptions}

Key findings of a recent consumer closure study indicate that screw caps had negative impact on consumer purchase intent. Only $45 \%$ of respondents indicated a wiliness to buy screw cap wines as compared to $94 \%$ of respondents willing to purchase natural cork wine. Screw cap wines hit their peak of consumer acceptance in 2007 and are now considered less appropriate for all occasions than they were in 2007 (Bleibaum, 2011). Few consumers (11\%) agree that screw cap wine closures represent wines of high or very high quality. The majority of consumers $(50 \%)$ seemed to indicate that screw cap wines convey low or very low quality wines (Bleibaum, 2011). Consumers perceive the 
appropriateness of a screw cap lower, and therefore, would not be inclined to purchase it more than they would a natural cork closure (Bleibaum, 2011).

Results of the study seem to indicate that US consumers still have a very low opinion of screw cap wines and this greatly impacts their willingness to purchase such wines. It seems to show that consumer attitudes towards screw cap wine's social acceptability had decreased across all occasion sets, indicating overall decline in consumer attitude towards screw cap wines. Base on the majority of respondents, the consensus still is that screw cap wines indicate low or very low quality wines. This ultimate consumer understanding most likely is a driver for declined purchase intent of screw cap wines (Bleibaum, 2011). This is a very significant study on consumer attitudes of screw cap wines. It is very important to have a vivid understanding of consumer views in order to make progress changing some of these consumer beliefs.

Tragon, a consumer research firm, conducted the study. A total of 1587 consumers were polled during the span of seven years (Bleibaum, 2011). This number of respondents is large enough to be statistically robust and spanned across such a long time, consumer opinions can change. One must think that the respondents were pulled from the same channels that Tragon had access to during the seven-year study. A number of variables could be attributed over all to consumer acceptance rates declining in 2011 such as limited market supply of screw cap wines. It might be worthwhile to replicate this study to see if that rate continued to decline in the future. 
As seen in the following figure, consumer opinion of screw caps has changed drastically over recent years. Appropriateness was highest in 2007 for casual situations, such as dinning at home and always least appropriate for special occasions, like a dinner party. Screw caps seemed to have reached their peak in consumer acceptance and are now less appropriate for all occasions than they were in 2007 (Bleibaum, 2011).

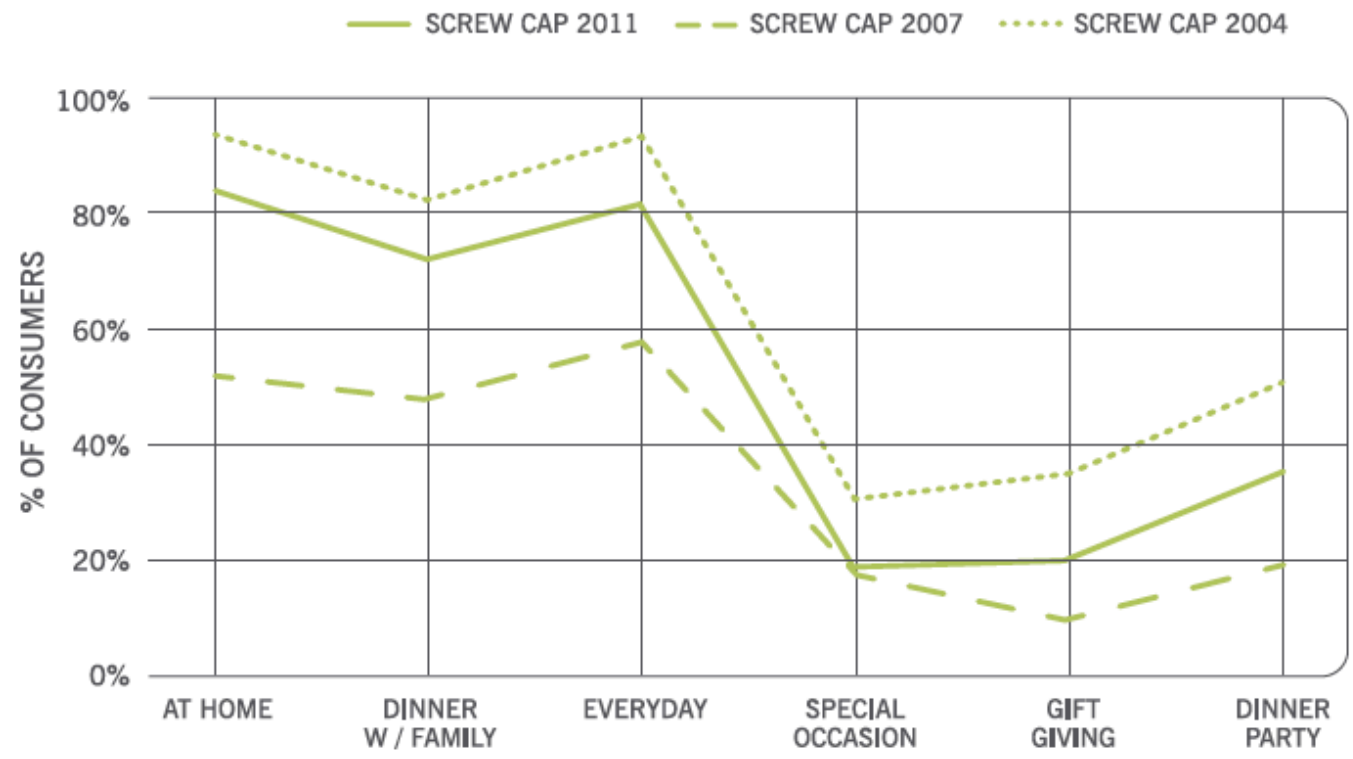

Figure 4: Consumer acceptance of screw cap wines over time (Bleibaum, 2011)

Natural cork was most appropriate for a dinner party, to give as a gift, and special occasion; whereas, all three closures were appropriate for an everyday wine, at home, and dinner with the family. Screw cap wine is the least appropriate wine every situation except everyday drinking (Bleibaum, 2011). 


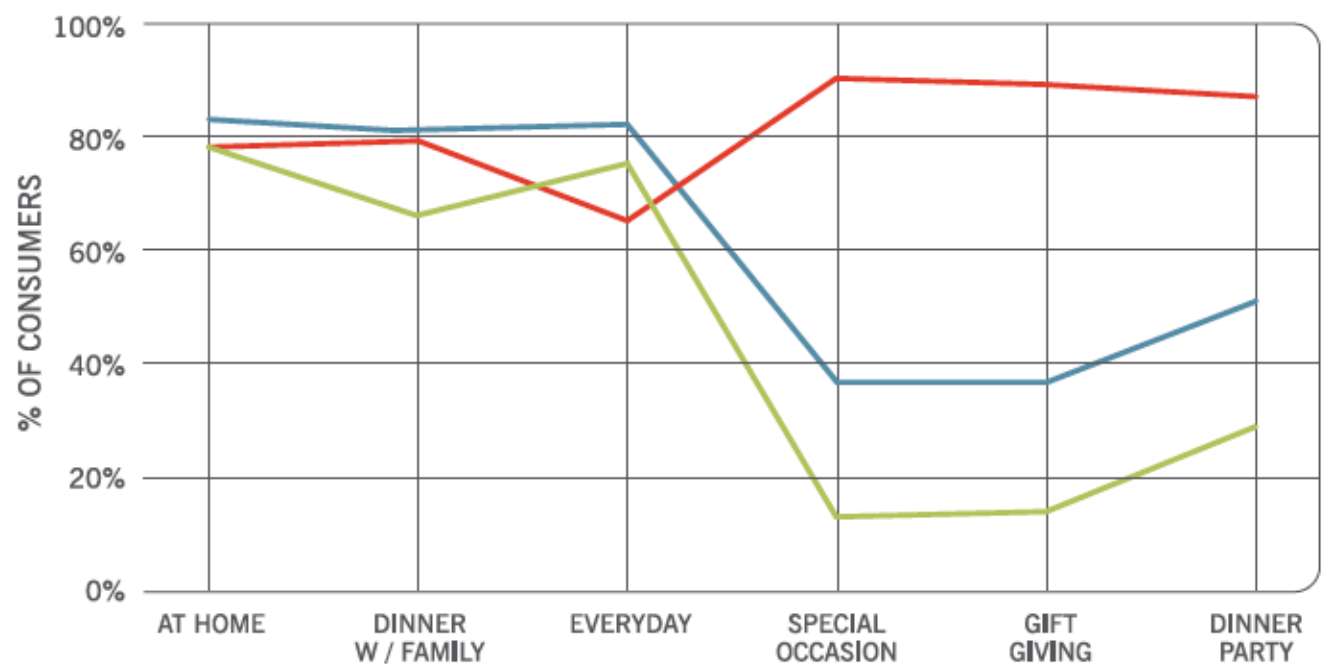

Figure 5: Appropriateness of closures by usage situation (Bleibaum, 2011)

Focusing on improving perceived value and image of screw cap wines could reduce risk barriers (Choi et al., 2010). One example of this is introducing mid-to-high end wines with screw caps. PlumpJack, a Napa Valley winery is an example of a winery implementing this strategy. This cue signals consumers to put more value in screw cap closures than other types of closures.

Emphasis needs to be placed on learning more about consumer attitudes, values and lifestyles to gauge whether screw caps will be compatible with the targeted winedrinking consumers. This consumer-centric focus may explain the discrepancy between consumer attitudes in different countries and can more effectively increase adoption. Regional consumer category needs to be taken in to consideration before implementing a one-size-fits-all marketing campaign strategy for screw cap wines (Choi et al., 2010). 
According to a study in 2007, only $34 \%$ of people polled would buy wine with a screw cap. In addition, $87 \%$ of the people surveyed disagreed with the statement: "I believe that wines with screw caps are higher in quality than those with natural cork," (Marin et al., 2007). This evidence indicates that there is a perceived, but perhaps not real, quality difference in wines with varying closure methods.

Five barriers to resistant innovation in regards to screw cap wine closures include: 1) Disruption: consumers enjoy tradition and status quo; they dislike learning new skills;

2) Risk: both social and psychological, such as friends' behavior or fear of being judged; 3) Misunderstanding value proposition: not being aware of the product benefits elimination of cork taint, no need for extraction tools and conveniently opens quickly, anywhere; 4) Deviation from the known: fears or doubts associated from delineating from social norms; 5) Negative product image: such as the notion that only cheap, high-alcohol wine is bottled with screw caps (Garcia et al., 2011).

\section{Removing Barriers}

To better address topics such as negative consumer perceptions and resistant technologies like screw cap wine closures, marketing and communication strategies can be integral to turning negative perceptions into positive ones. Marketing alliances (pooling money into a common marketing campaign) are powerful tools in the adoption of resistant technologies such as screw cap wine closures. 


\section{Communication strategies}

Communication strategies need to be devised in order to educate key stakeholders such as screw cap wine distributers. Distributors are by far the most important stakeholders as they are the gateway to the consumer, the wine press, and wine media. They have the largest potential to influence the wine trade via word of mouth promotion (Wilson \& Lockshin, 2003).

Producers of crew caps need to respond to any and all inquiries from distributors regarding performance and production of screw cap closures. Any inconsistencies in communication could lead to fallacies and large miscommunications that extend through the chain including wine media and consumers (Wilson \& Lockshin, 2003).

Campaigns must reach out to all relevant stakeholders including hospitality, retailers and wine media. Two messages need to be consistently delivered in marketing campaigns: screw cap wines deliver integrity and they are reliable (Charters \& Pettigrew, 2006). Screw cap wine closures present a new alternative to natural cork closures, but in order for this new closure product to be successful all parts of the distribution channel need to become aware of its problems and benefits (Wilson \& Lockshin, 2003).

\section{Consumer Education}

Wine education may play a key role in determining whether screw cap wines can become more socially acceptable (Bleibaum, 2011). Consumer education still remains a critical step in consumer adoption of screw caps in the U.S. market. Education needs to 
be delivered effectively with a unified message conveying how screw caps drastically eliminate cork taint for consumer consumption and consistently keep wine just as the winemaker intended (Wilson \& Lockshin, 2003).

\section{Marketing Alliances}

In 2000, a group of 15 winemakers from the Clare Valley in Australia came together to market a campaign called, "Riesling with a Twist." These fifteen stakeholders all shared the fundamental belief that screw cap wines maintained wine quality and that these closures consistently delivered a high quality product. As a cooperative, they pooled resources to invest in direct marketing, packaging fliers, emails, website chats (Choi et al., 2010).

"Riesling with a Twist" partners' hosted wine tasting events targeting wine critics and end consumers. These tasting events were used to demonstrate quality aspects of screw cap wine closures. The campaign was so successful that in 2011, most Australian wineries sought out screw cap wines for their product lines (Choi et al., 2010).

Success was the ultimate measure for this first screw cap wine alliance. New Zealand quickly followed suit. In 2001, 27 New Zealand wineries came together to form the New Zealand Screw Cap Wine Initiative (NZ Initiative). The NZ Initiative quickly expanded to 50 wineries in 2005 (Garcia et al., 2011). 
The key framework adopted from the NZ Initiative included advancing common goals and establishing strong leadership within the alliance. The sole purpose of the alliance was to: 1) promote the use of screw cap wine closures, 2) provide wineries with manufacturing means to produce screw cap wines and 3) educate wine trade, press and consumers (Choi et al., 2010).

By sharing investment costs, minimizing market risks and pooling resources for marketing and screw cap manufacturing, the U.S. wine industry could penetrate more available wine market share (Garcia et al., 2011). U.S. Wine industry investments in good screw cap marketing campaigns would translate into substantial revenue gains.

\section{Chapter Summary}

There are still negative consumer attitudes towards screw cap wines; image and value barriers still exist. Consumer education still remains a critical step in consumer adoption of screw caps in the U.S. market. Education needs to be delivered effectively with a unified message conveying how screw caps drastically eliminate cork taint for consumer consumption and consistently keep wine just as the winemaker intended. U.S. wineries need to create co-operative marketing alliances that will communicate this message and signal to consumers to prepare for serious permanent change, thus reducing consumer psychological switching costs. This may be the change needed to create more consumer acceptance and increase screw cap market share in the United States. 
Although the studies reviewed in this chapter deliver impactful information about consumer attitudes toward screw cap wines, they lack vital demographic data, or surveyed too small a respondent pool. Alternative closures have received a fair amount of attention in academic research but less is known about consumer attitudes about screw cap wines. This current study of Consumer Purchase Decisions regarding Screw Cap Wines will contribute to the existing literature by finding factors that influence consumer purchase decisions relative to closure type. 


\section{CHAPTER 3 METHODOLOGY}

\section{Introduction}

This chapter describes methods, how survey instruments were selected, how information regarding the pilot study, sample selection, procedures, data analysis and a summary were handled.

An online survey was made available for six weeks from February 2, 2009 March 16, 2009 via web platforms including Facebook and Craigslist. This survey was used to collect quantitative data which measured consumer behaviors regarding screw cap wines, demographics of wine drinking consumers, perceptions of wine quality, and social assessments regarding screw cap wine consumption. The survey consisted of twenty-nine questions including an Informed Consent Form and could be completed within fifteen to twenty minutes.

\section{Instrument Design}

The survey used for this study was adapted from "Effects of Wine Bottle Closure Type on Purchase Intent (Marin \& Durham, 2007) and "Conjoint research for consumer perception of wine closure options and their impact on purchase interest in the United States and Australia" (Bleibaum et al., 2005). Additionally, demographics related questions were adapted from "Dimensions of wine region equity and their impact on consumer preferences" study (Orth, Wolf, \& Dodd, 2005). Marin cited that one of the drawbacks to the study first conducted on consumer perception of wine was the lack of demographic information collected. With this in mind, the purpose of the survey was to 
duplicate the previous study but utilize vital consumer data and measure consumer perceptions in more detail. The survey was compiled using Survey Monkey, an online survey manager.

\section{Pilot Study}

A pilot study was conducted to improve the reliability of the instrument. The pilot study was available online between the period of January 26, 2009 and February 9, 2009, with a beta testing group of thirty-five respondents. The thirty-five respondents were provided with informed consent paperwork before the survey was administered. They were encouraged to spot words, phrases, instructions and question flows that seemed confusing. This pilot study was completed to improve these mentioned aspects of the survey. The beta group was able to provide valuable feedback to the overall instrument design.

Sample

A thorough sample was collected. This sample consisted of 417 participants, of which, 319 completed the survey $(n=319)$. Participants were invited online via multiple Craigslist listings inviting community members to participate in a wine survey. Additionally, the survey was posted on a Facebook fan page for wine enthusiasts. The reason these particular venues were chosen was to reach a diverse group of wine consumers, including age, income, gender and geographic location within California. A response rate of people who viewed the survey, versus participants who took part in the survey, was $66.7 \%$. This respondent sample represents wine drinkers in California. The 
survey that was launched, while statistically significant, was not a nationally conducted survey.

\section{Data Collection}

The Human Subject Committee approved this survey. It was available for six weeks from February 2, 2009 - March 16, 2009. The invitations to participate in the survey were solicited online via Facebook, Craigslist San Francisco, Craigslist San Diego and Craigslist Los Angeles. Participants read an informed consent document, and indicated agreement to the consent by continuing to participate in the survey. Participants were told that the purpose of the study was to collect consumer information regarding wine closures. No information regarding specific research questions was given.

The online survey showed the participant's progress of survey completion in a bar above the survey while they filled it out. The data was compiled and collected by Survey Monkey. The responses were tracked and time stamped. Survey Monkey managed all analytics regarding participants and insured that all participants were unique by verifying user IP addresses. Survey Monkey was used to collect responses but these collected responses were then imported into SPSS 20 for further analysis.

\section{Data Analysis}

All data analysis was performed using SPSS version 20. Demographics, consumer purchase and spending behaviors were summarized using descriptive statistics. The results of this work were presented in the sample statistics table, which can be found in the appendix of this study. Data regarding respondents gender, income, marital status, 
age, education, employment status, wine course history, wine purchase history, wine preference, wine purchase location preference, wine knowledge and wine closure preference by social occasion were collected and analyzed using multiple tests and models (see Appendix: Planned Analyses).

The research questions for this study were evaluated using a variety of statistical significance tests. For research question 1a, logistic regression (binary logit model) was used as well as a chi-squared test to examine gender differences, age, income, education, marital status and wine knowledge in consumer purchase decisions to buy screw cap wines. For research question $1 \mathrm{~b}$, ordinary least squares regression (OLS) was used to evaluate the number of screw cap wine bottles purchased per month. For this research question, an independent sample t-test was also prepared to examine gender differences alongside number of bottles of screw cap wine purchased per month. The reason multiple tests were performed was due to the nature of the dependent variables. For yes/no decisions to purchase screw cap wines, logistic analyses were used due to the bivariate nature of the dependent variable. For amount of screw cap wine bottles purchased per month, Ordinary Least Squares (OLS) models were used because of the continuous nature of the dependent variable.

For research question 2a, a general linear model (GLM), or flexible generalization of ordinary linear regression allowing for response variables that have other than a normal distribution was used to determine the perceived social appropriateness of various closure types and how they differ according to social occasion. For research question $2 b$, 
the likelihood of consumers bringing screw cap wines to social gatherings was evaluated using logistic regression (binary logit model). The logistic approach was chosen based on the binary outcome of the dependent variable, likelihood to purchase screw cap wines (likely or unlikely). A table has been provided in the appendix outlining the methodology used in all data analysis for this study.

\section{Summary}

An online survey was used to explore consumer attitudes toward screw cap wines. This survey was adapted from Effects of Wine Bottle Closure Type on Consumer Purchase Intent and Price Expectation (Marin and Durham 2007) and Conjoint research for consumer perception of wine closure options and their impact on purchase interest in the United States and Australia (Bleibaum et al., 2005). A pilot study was conducted to improve the reliability of the survey instrument. This survey was made available for six weeks from February 2, 2009 - March 16, 2009 via web platforms including Facebook and Craigslist. The sample included 417 online respondents, of which, 319 respondents completed the survey $(\mathrm{n}=319)$. The survey was designed, administered and managed online by Survey Monkey, an online survey tool. The results of the survey appear in the following chapter. 


\section{CHAPTER 4 RESULTS}

\section{Sample Statistics}

A total of 319 people participated in the survey. There were slightly more males than females who took this survey (males represented 50.7\%, females represented 49.3\%). Most respondents fell between the ages of 21-30. But, respondents from all legal drinking ages were generally well represented in the study.

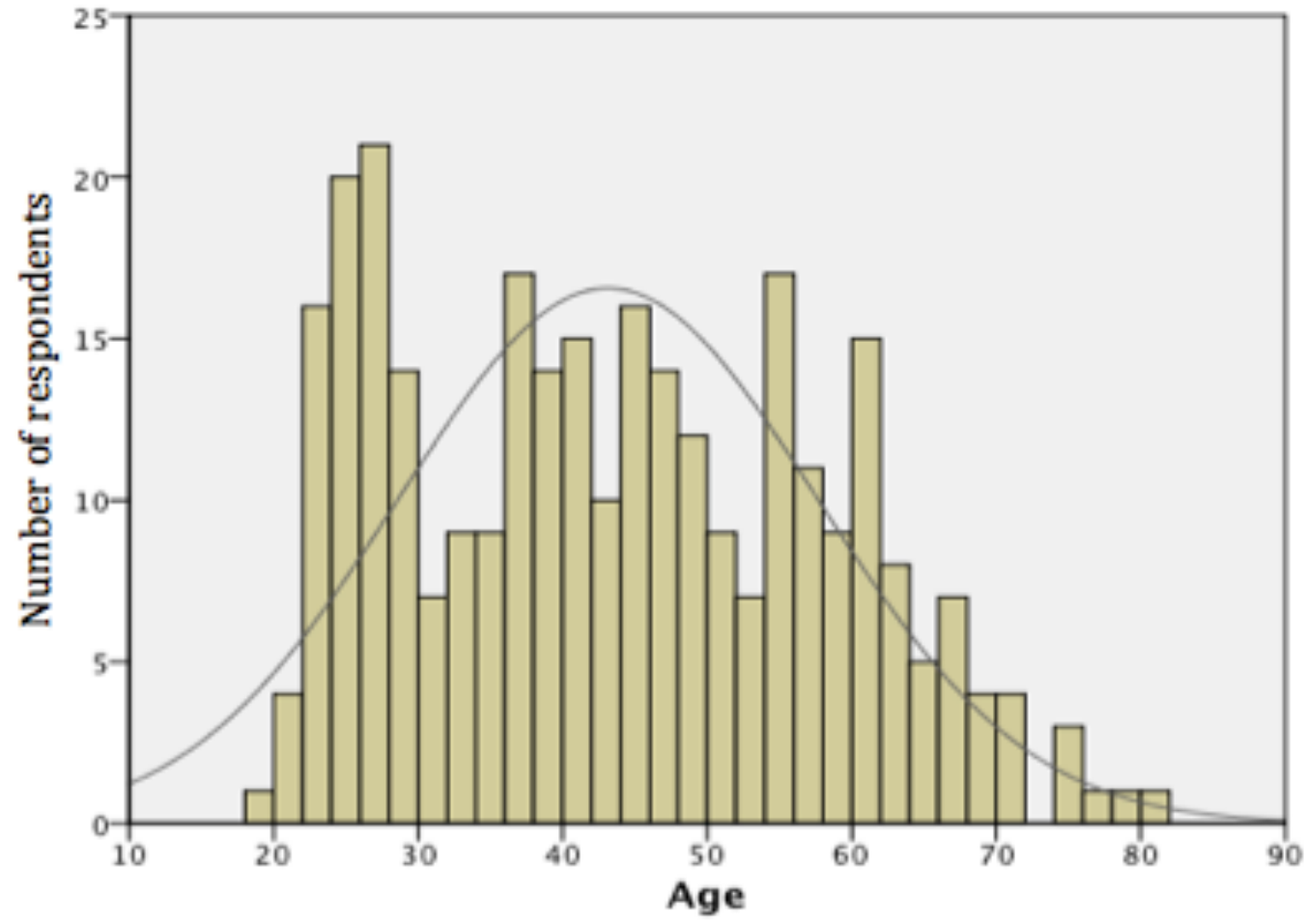

Figure 6: Age histogram of respondents 
The mean (or average across all respondents in the distribution) age of respondents was 43 years old. The mode (or most common score in the distribution) was 26 years old. The disparity in the numbers is likely due to the online nature of this study, whereby a younger audience tends to be more comfortable with such technology, although this is changing with time.

Table 1: One-sample statistic of age

\begin{tabular}{|l|r|r|r|c|}
\hline & $\mathrm{N}$ & Mean & Std. Deviation & $\begin{array}{c}\text { Std. Error } \\
\text { Mean }\end{array}$ \\
\hline Age & 301 & 43.13 & 14.501 & .836 \\
\hline
\end{tabular}

Married people were the most common group at $49.7 \%$ of all respondents. Other marital statuses included: Single (41.8\%), Other (7.6), and Separated (1.0\%). It should be noted that others were most often reported as in Domestic Partnerships.

The majority of respondents $(81.1 \%)$ did not have children. This is followed by a smaller percent having one child $(9.5 \%)$, two children $(7.1 \%)$, three children $(1.4 \%)$, and four children $(1.1 \%)$.

In regards to education, the largest category of respondents have completed PostGraduate work (38.4\%). The second largest education level completed was College (35.4\%), followed by Some College (21.6\%), High School (3.0\%), Some High School $(1.0 \%)$ and Grade School (0.7\%). 


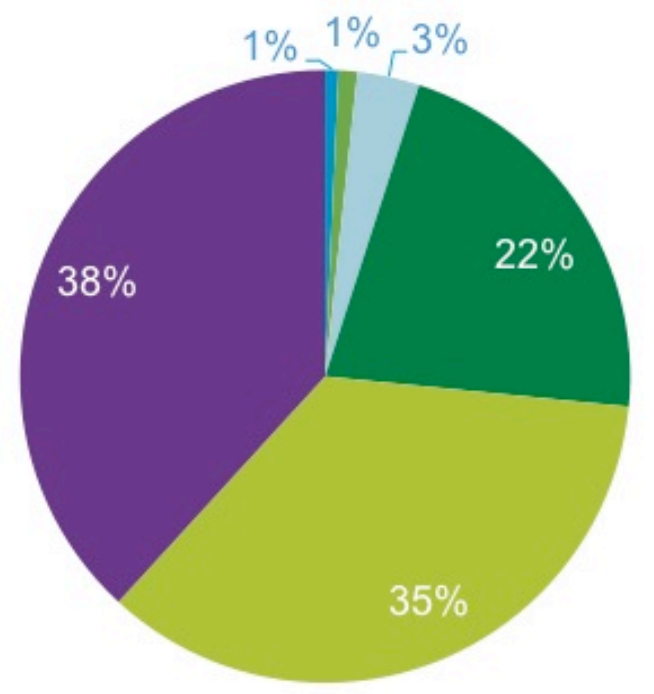

- Grade school or less

- Some High School

- High School Graduate

- Some college

- College Graduate

- Post-Graduate Work

Figure 7: Highest level of education

A little less than three fourths of the respondents or $74.2 \%$ have never taken a wine appreciation course.

There were $78.9 \%$ of respondents that reported belonging to a wine club while $21.2 \%$ reported they did not belong to a wine club. The largest percent of wine club members $(17.3 \%)$ do not receive screw cap wines in their shipments.

Most people were employed full time (56.8\%). This was followed by part-time employment (13.9\%) and retirees $(11.2 \%)$. Of the remaining people surveyed, $10.2 \%$ were unemployed. Additionally, other employment was listed at 5.9\% and stay at home parents at $2.0 \%$. 


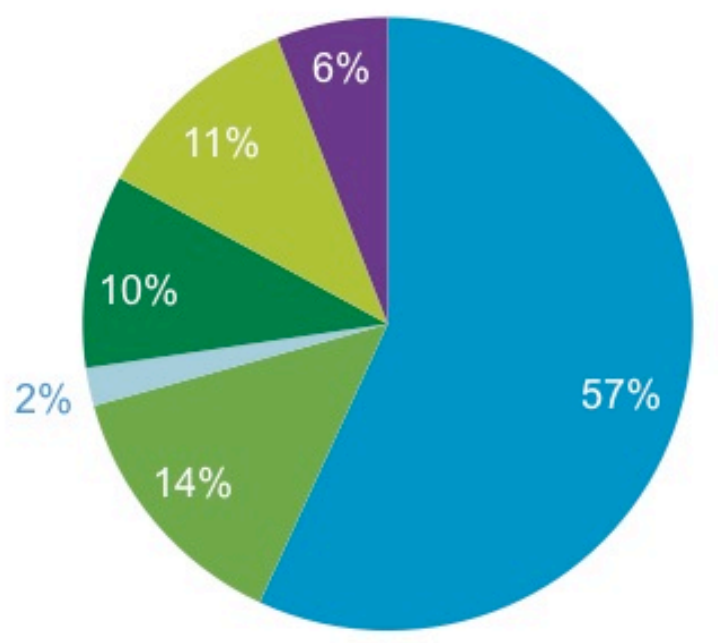

-Employed, Full-time - Employed, Part-time m Stay at home Parent - Not employed - Retired - Other

Figure 8: Employment status

Nearly $35 \%$ of respondents reported $\$ 100,000+$ as an annual income. Ten percent of respondents report $\$ 71,000-\$ 80,000$ per year. And followed third, $9.3 \%$ respondents reported $\$ 41,000$ - $\$ 50,000$ in income per year. 


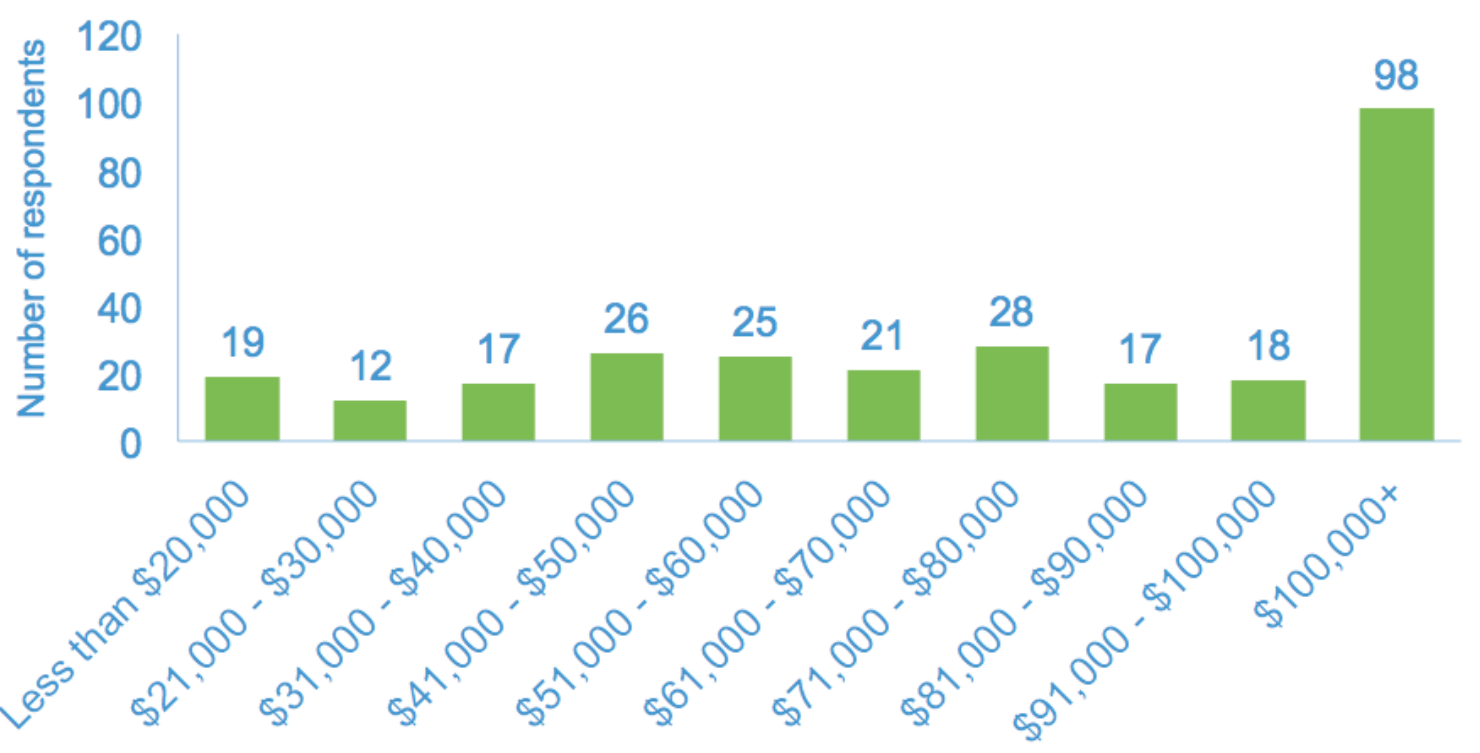

Figure 9: Reported annual household income

Summarizing the demographics of the survey, nearly $50 \%$ of respondents' marital status was married. There were approximately equal numbers of males and females. Most respondents did not have children, were college educated, employed full-time, had incomes of $\$ 100,000$ or less and were not part of a wine club. This sample does not represent a typical US population, but does represent a typical wine drinker, living in California. 
Table 2: Demographic Variable Summary

Demographic Variable Summary

\begin{tabular}{lccccccc}
\hline & \multicolumn{3}{c}{ Percent } & & & & \\
\hline Demographic Variables & Yes & No & Mean & Std. Error & Mode & $\begin{array}{c}\text { Std. } \\
\text { Dev. }\end{array}$ & N \\
\hline Marital Status (Single) & $49.7 \%$ & $50.3 \%$ & ---- & ---- & ---- & ---- & 304 \\
Gender (Female) & $49.3 \%$ & $50.7 \%$ & ---- & ---- & ---- & ---- & 304 \\
Age (in years) & ---- & ---- & 43.13 & .836 & 26 & 14.501 & 301 \\
\hline Number of children in household & ---- & ---- & .32 & .044 & 0 & .750 & 296 \\
\hline Level of education (1-6) & ---- & ---- & 5.05 & .055 & 6 & .955 & 305 \\
Income (1-10) & ---- & ---- & 6.86 & .181 & 10 & 3.029 & 280 \\
Employed & ---- & ---- & ---- & ---- & ---- & ---- & 303 \\
$\quad$ Employed, full-time & $56.8 \%$ & ---- & ---- & ---- & ---- & ---- & 172 \\
Employed, part-time & $13.9 \%$ & ---- & ---- & ---- & ---- & ---- & 42 \\
Stay at home parent & $2.0 \%$ & ---- & ---- & ---- & ---- & ---- & 6 \\
Not employed & $10.2 \%$ & ---- & ---- & ---- & ---- & ---- & 31 \\
Retired & $11.2 \%$ & ---- & ---- & ---- & ---- & ---- & 34 \\
Other & $5.9 \%$ & ---- & ---- & ---- & ---- & ---- & 18 \\
\hline Wine club membership (yes) & $21.1 \%$ & $78.9 \%$ & ---- & ---- & ---- & ---- & 303 \\
\hline Wine club offers screw cap wines & ----- & ---- & ---- & ----- & ---- & ----- & 255 \\
\hline Yes & $17.3 \%$ & ---- & ---- & ---- & ---- & ---- & 44 \\
No & $11.4 \%$ & ---- & ---- & ---- & ---- & ---- & 29 \\
\hline Not part of a wine club & $71.4 \%$ & ---- & ---- & ---- & ---- & ---- & 182 \\
\hline
\end{tabular}

\section{Consumer Behaviors}

Of all respondents polled, $99 \%$ of respondents drink wine. Of all types of alcoholic beverages, wine was most popular with $97.50 \%$ of respondents having consumed it within the last year. This is followed by beer $(83.10 \%)$, mixed drinks $(75 \%)$, sparkling wine $(70.30 \%)$ and other $(37.80 \%)$. 


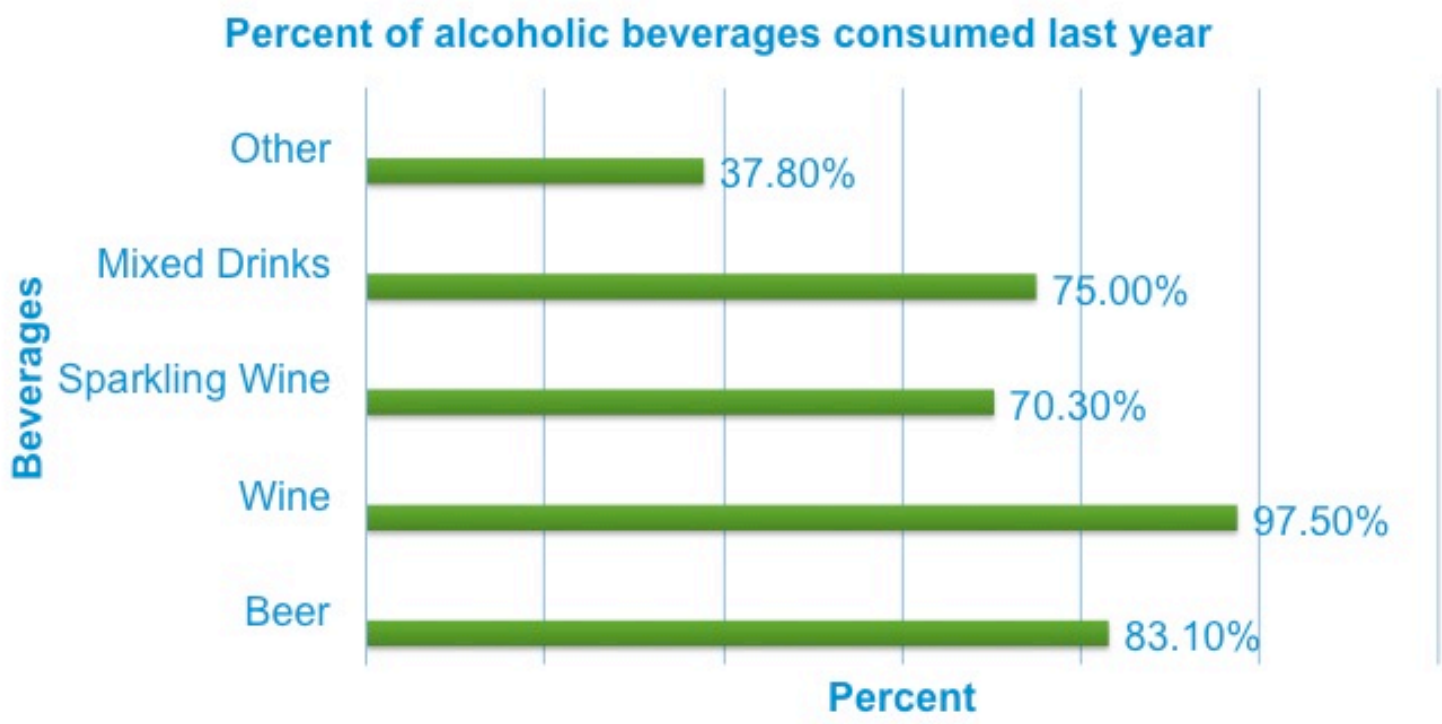

Figure 10: Percent of alcoholic beverages consumed last year by respondent

Nearly $34 \%$ of respondents who took this survey do not purchase screw cap wines. Respondents predominately purchase red wine, whether in a screw cap bottle or not. Of screw cap wine purchases, $34 \%$ of respondents most frequently purchase red wine and $29 \%$ of respondents most frequently purchased white wine.

Respondents spent an average of $\$ 109.47(\mathrm{SD}=\$ 127.54)$ per month on wine, with $\$ 84.76$ on red wine and $\$ 38.74$ on white wine. This represents a typical sample of wine drinkers in California. The median was $\$ 60$ with half of all monthly purchases above or below this point. The minimum amount of wine purchases per month was zero and the maximum $\$ 800$. However, one participant reported spending $\$ 75,000$ per month on wine. While this data point seemed valid in all other respects, it was chosen to be omitted from the dataset due to it being a strong outlier. 
For total monthly wine purchases made, $31.7 \%$ of respondents purchased at least one wine which fell between the $\$ 15.00$ - $\$ 19.99$ range. The second most popular category of purchase was the $\$ 0.00-\$ 4.99$ range, which $31.50 \%$ of respondents had purchased at least one bottle of wine in the last month within that price range.

Of total monthly screw cap wine purchases made, $53.8 \%$ of respondents purchased at least one screw cap wine that fell between the $\$ 0.00-\$ 4.99$ range. The second most popular categories of purchase were both the \$20.00-\$25.99 and \$26+ range.

The grocery store is the primary source of wine purchases for $41.2 \%$ of respondents. Other popular wine purchase destinations included: Wine Specialty Shops (18.3\%), Liquor Stores (14.1\%) and Other (10\%), of which, online purchases were most common. 


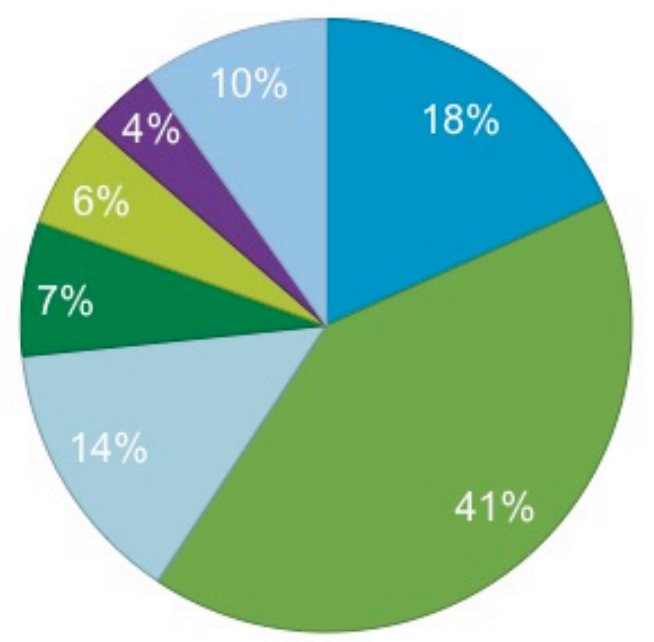

Wine Specialty Shop

- Grocery Store

Liquor Store

Winery

Wholesale Discount Store

-Wine Club

Figure 11: Primary wine purchasing locations

The majority of respondents agreed with the statement "I would buy wine with a synthetic cork," while $6.8 \%$ disagreed. To the statement, "I would buy wine with a natural cork," 99.6\% agreed. When posed with the statement, "I would buy wine with a screw cap," only $76.6 \%$ of respondents agreed.

When asked, "Would you be disappointed if wine purchased at a restaurant came with a screw cap?" $59 \%$ of respondents agreed that they would be disappointed. While $81 \%$ of respondents disagreed that they would send a screw cap wine back if received in a restaurant, 19\% said that they would send screw cap wine back if it was ordered. 
Table 3: Agreement statements for closure method

\begin{tabular}{|l|r|r|c|}
\hline Agreement Statements & \multicolumn{1}{|c|}{ Agree } & \multicolumn{1}{c|}{ Disagree } & \multicolumn{1}{|c|}{$\begin{array}{c}\text { Response } \\
\text { Count }\end{array}$} \\
\hline I would buy wine with a synthetic cork & $\mathbf{9 3 . 2 \% ~ ( 2 6 2 ) ~}$ & $6.8 \%(19)$ & 281 \\
\hline I would buy wine with natural cork & $\mathbf{9 9 . 6 \% ( 2 8 2 )}$ & $0.4 \%(1)$ & 283 \\
\hline I would buy wine with a screw cap & $\mathbf{7 9 . 6 \% ( 2 2 3 )}$ & $20.4 \%(57)$ & 280 \\
\hline $\begin{array}{l}\text { I believe that wines with synthetic corks are } \\
\text { higher in quality than those of natural cork }\end{array}$ & $8.3 \%(23)$ & $\mathbf{9 1 . 7 \% ( 2 5 4 )}$ & 277 \\
\hline $\begin{array}{l}\text { I believe that wines with screw caps are higher } \\
\text { in quality than those of natural cork }\end{array}$ & $6.5 \%(18)$ & $\mathbf{9 3 . 5 \% ~ ( 2 5 8 )}$ & 276 \\
\hline $\begin{array}{l}\text { I would be disappointed if I bought a wine at a } \\
\text { restaurant and it came with a synthetic cork }\end{array}$ & $16.7 \%(47)$ & $\mathbf{8 3 . 3 \% ( 2 3 4 )}$ & 281 \\
\hline $\begin{array}{l}\text { I would be disappointed if I bought a wine at a } \\
\text { restaurant and it came with a screw cap }\end{array}$ & $41.5 \%(117)$ & $\mathbf{5 8 . 5 \% ( 1 6 5 )}$ & 282 \\
\hline $\begin{array}{l}\text { In a restaurant, I would send back a wine that } \\
\text { came with a synthetic cork }\end{array}$ & $3.6 \%(10)$ & $\mathbf{9 6 . 4 \% ~ ( 2 7 0 )}$ & 280 \\
\hline $\begin{array}{l}\text { In a restaurant, I would send back a wine that } \\
\text { came with a screw cap }\end{array}$ & $18.9 \%(53)$ & $\mathbf{8 1 . 1 \% ( 2 2 7 )}$ & 280 \\
\hline
\end{tabular}

Figure 12 shows self assessed wine knowledge by respondents. When asked to rate personal wine knowledge from 1-10 ( 1 being little to no wine knowledge and 10 being a great deal of knowledge), seventeen percent of respondents rated themselves as 5 . A t-test determined the average wine drinker's wine knowledge at 5.92 


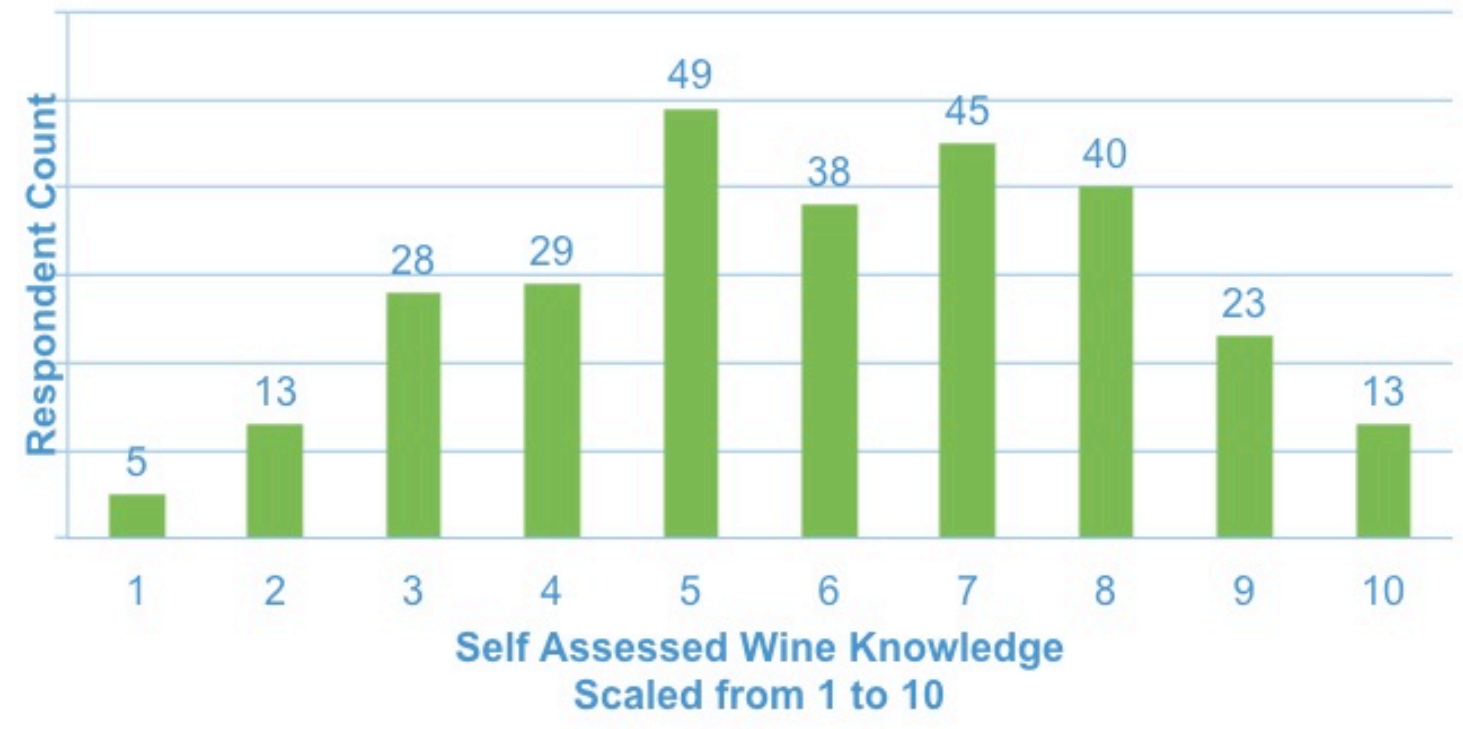

Figure 12: Self-assessed wine knowledge

Research question Testing

To evaluate the research question 1a: (Age, gender, income, education, marital status, wine classes taken, amount spent on wine per month and wine knowledge where examined to evaluate their relationship with screw cap wines purchases), a chi-squared analysis testing for gender differences and a logistic regression (binary logit model) for age, income, wine knowledge and were used due to the binary nature of the dependent variable, decision to purchase screw cap wines (yes/no). Logistic regression models predict the probability (or likelihood) of an outcome using a logarithmic function (e). The basic equation for logistic regression models is presented below for models with one independent variable. This formula is expanded for models with additional variables.

Basic equation for logistic regression

$$
P(Y)=\frac{1}{1+e^{-\left(b_{0}+b_{1} X_{1}+\varepsilon_{i}\right)}}
$$




\section{Expanded equation for linear regression}

$$
\begin{aligned}
& P(Y)=\frac{1}{1+e^{-\left(b_{0}+b_{1} X_{1}+b_{2} X_{2}+\ldots+b_{n} X_{n}+\varepsilon_{i}\right)}} \\
& \mathrm{P}(\mathrm{Y})=\text { probability of } \mathrm{y}(\text { the dependent variable) } \\
& \mathrm{e}=\text { logarithmic function (log) } \\
& \mathrm{b}_{0}=\text { constant } \\
& \mathrm{b}_{1 \ldots} \mathrm{b}_{\mathrm{n}}=\text { regression coefficients } \\
& \mathrm{X}_{1 \ldots} \mathrm{X}_{\mathrm{n}}=\text { value of the independent variable(s) }
\end{aligned}
$$

The chi-squared test determined that there were no significant gender difference in the decision to purchase screw cap wine, $\left.\chi^{2}(1, N=279)=.036, p=.850\right)$.

Table 4: Results of Chi-square Analysis of Decision to Purchase Screw Cap Wine by Gender

\begin{tabular}{lrr} 
& \multicolumn{1}{c}{ Men } & \multicolumn{1}{c}{ Women } \\
\cline { 2 - 3 } & $\mathrm{n}=138$ & $\mathrm{n}=141$ \\
\hline Not Purchase SC & $9(47.4 \%)$ & $10(52.6 \%)$ \\
Purchase SC & $129(49.6 \%)$ & $131(50.4 \%)$ \\
\hline
\end{tabular}

Row percentage reported in table.

$* p \leq .05, * * p \leq .01, * * * p \leq .001$

Using a binary logit model, age, income and wine knowledge were run independently. When running the model using decision to purchase screw cap wine as a dependent variable, age was used a sole independent variable. In this individual test, age was found to not be significant when looked at alone. An additional binary logit test was run to determine if income was significant when looking at consumer's decision to purchase screw cap wines. In this individual model, income was found to be significant at the $\mathrm{p} \leq .01$ level $\left(\mathrm{b}=.246\right.$, Wald $\left.\chi^{2}(1)=8.152, \mathrm{p} \leq .01\right)$. As income increased, so did the 
likelihood of buying screw cap wine. It should be noted that wine knowledge was also run individually through this model and no significance was found.

$$
P(Y)=\frac{1}{1+e^{-(4.061+-.030(\text { age })}}
$$

Table 5: Individual Model Results: Decision to Purchase Screw Cap Wine

Binary Logit Model

\begin{tabular}{lllc}
\hline Variables & $\beta$ & SE $\beta$ & $95 \%$ CI \\
\hline Age (in years) & -.030 & .017 & {$[.938,1.003]$} \\
(Constant) & 4.061 & & \\
\hline Income (1 to 10) & $.246^{* *}$ & .086 & {$[1.080,1.515]$} \\
(Constant) & 1.171 & & \\
\hline Wine knowledge (1 to 10) & -.053 & .109 & {$[.767,1.174]$} \\
(Constant) & 2.941 & & \\
\hline
\end{tabular}

${ }^{*} p \leq .05, * * p \leq .01, * * * p \leq .001$

When running the binary logit regression with multiple independent variables such as age, gender, income, education level, marital status, wine classes taken, monthly wine expenditures and wine knowledge, age was found to be significant at the $p \leq .01$ level $\left(b=-.070\right.$, Wald $\left.\chi^{2}(1)=8.019, p \leq .01\right)$. This means, that as respondents age, they become less likely to purchase screw cap wines. Additionally, income was found to be significant at the $\mathrm{p} \leq .05$ level $\left(\mathrm{b}=.246\right.$, Wald $\left.\chi^{2}(1)=3.789, \mathrm{p} \leq .05\right)$, meaning that as respondents' income increases, they are more likely to purchase screw cap wine.

As additional variables were added to the model, the relationship between factors became clearer as the model explained more about the decision to buy screw cap wine. This explains more of the variance so one has a better understanding of what drives the outcome of the dependent variable. In this case, age, seen above, was tested alone and 
was not significant in regards to the decision to purchase screw cap wines. In the second model, as mentioned above, age does in fact become significant, along with income.

Table 6: Results Decision to Purchase Screw Cap Wine

Binary Logit Model

\begin{tabular}{lccc}
\hline Variables & \multicolumn{1}{c}{$\beta$} & SE $\beta$ & $95 \%$ CI \\
\hline Age & $-.070^{* *}$ & .025 & {$[.888, .979]$} \\
Gender (female) & .403 & .635 & {$[.431,5.193]$} \\
Income & $.242^{*}$ & .124 & {$[.998,1.625]$} \\
Education & .286 & .273 & {$[.779,2.274]$} \\
Marital status (single) & .863 & .774 & {$[.520,10.800]$} \\
Wine class (yes) & 1.335 & .874 & {$[.685,21.095]$} \\
Wine purchase monthly (\$) & .000 & .002 & {$[.995,1.005]$} \\
Wine knowledge (1 to 10) & -.229 & .154 & {$[.588,1.076]$} \\
(Constant) & 3.726 & & \\
\hline
\end{tabular}

$* p \leq .05, * * p \leq .01, * * * p \leq .001$

$$
P(Y)=\frac{1}{1+e^{+.863(\text { maritalstatus })+1.355(\text { wineclass })+.000(\$ \text { wine })+-.299(\text { wineknowledge })}}
$$

While testing research question $1 \mathrm{~b}$, evaluating if age, gender, income, education, marital status, wine classes taken, amount spent on wine per month and wine knowledge affect the number of bottles of screw cap wines purchased per month, ordinary least squares regression (OLS) was used to evaluate the number of screw cap wine bottles purchased per month. The basic equation for linear regression with a single independent variable is presented below. The equation is expanded when multiple independent variables are included in the model. An independent sample t-test was also prepared to examine gender differences alongside number of bottles of screw cap wine purchased per month. 


\title{
Basic equation for linear regression
}

\author{
$\Lambda$$$
Y=a+b X
$$ \\ $\mathrm{Y}=$ estimated value of dependent variable \\ $\mathrm{a}=$ constant \\ $\mathrm{b}=$ regression coefficient \\ $\mathrm{X}=$ value of the independent variable(s)
}

Individual OLS models were run to determine how the dependent variable, number or screw cap wine bottles purchases was affected by the various independent variables separately, such as age, income and wine knowledge. In the individual OLS model that tested how age affects the number of screw cap wine bottles purchase, the finding is significant at the $\mathrm{p} \leq .01$ level $(\beta=.230, \mathrm{p} \leq .01)$.

$$
\mathrm{Y}=-.115+.053(\text { age })
$$

This says that as respondents increase in age, they purchase more screw cap wine bottles. Individually run, income was found to also be significant at the $\mathrm{p} \leq .05$ level $(\beta=$ $.169, \mathrm{p} \leq .05)$. This information indicates that as income increases, the number of screw cap bottles of wine purchased also increases. Wine knowledge, when run individually using OLS was not found to be significant.

$$
\mathrm{Y}=.831+.198(\text { income })
$$


Table 7: Summary of Screw Cap Wine Bottles Purchased Last Month

Ordinary Least Squares Regression

\begin{tabular}{lllcc}
\hline Variables & $b$ & SE $\beta$ & $\beta$ & $95 \%$ CI \\
\hline Age (in years) & $.053^{* * *}$ & .015 & .230 & {$[.023, .082]$} \\
(Constant) & -.115 & .674 & & \\
\hline Income (1 to 10) & $.198^{*}$ & .081 & .169 & {$[.038, .357]$} \\
(Constant) & .831 & .612 & & \\
\hline Wine knowledge (1 to 10) & .377 & .101 & .250 & {$[.178, .576]$} \\
(Constant) & -.110 & .655 & & \\
\hline
\end{tabular}

${ }^{*} p \leq .05,{ }^{* *} p \leq .01, * * * p \leq .001$

Using an independent samples t-test to evaluate how gender affects purchasing screw cap wine, results indicate that gender is very much a significant variable $(\mathrm{p} \leq .001)$ in regards to bottles purchased last month (the dependent variable), $t(214.339)=2.62$, $\leq .001$. On average, men purchased more bottles (Mean=2.68) than women $(\mathrm{M}=1.53)$.

Table 8: Gender Differences in Number of Screw Cap Wine Bottles Purchased Last Month

\begin{tabular}{ccccc}
\hline$\frac{\text { Females }}{\mathrm{M}(\mathrm{SD})}$ & $\underline{\text { Males }}$ & $t$ & $d f$ & $95 \% \mathrm{CI}$ \\
\hline $1.53(2.75)$ & $2.68(3.98)$ & $2.62 * * *$ & 214.339 & {$[.291,1.999]$} \\
\hline$* p \leq .05, * * p \leq .01, * * * p \leq .001$ & & &
\end{tabular}

A multiple OLS test model was run to examine how independent variables such as age, gender, income, education, marital status, wine classes taken, monthly wine expenditures and wine knowledge, collectively, affect the number of screw cap wine 
bottles purchased. Of these variables, wine knowledge was found to be very significant at the $\mathrm{p} \leq .001$ level. As shown below in Table 9, as wine knowledge increases, the number of screw cap wine bottles also increases $(\beta=.087, \mathrm{p} \leq .001)$.

Table 9: Results Number of Screw Cap Wine Bottles Purchased Last Month Ordinary Least Squares Regression

\begin{tabular}{llccc}
\hline Variables & \multicolumn{1}{c}{$b$} & SE $\beta$ & $\beta$ & $95 \%$ CI \\
\hline Age & .025 & .021 & .099 & {$[-.016, .066]$} \\
Gender (female) & -.337 & .544 & -.048 & {$[-1.410, .736]$} \\
Income & -.188 & .103 & -.151 & {$[-.392, .017]$} \\
Education & .219 & .272 & .056 & {$[-.317, .755]$} \\
Marital status (single) & 1.050 & .589 & .149 & {$[-.112,2.212]$} \\
Wine class (yes) & -.353 & .554 & -.045 & {$[-1.447, .741]$} \\
Wine purchase monthly (\$) & .011 & .002 & .386 & {$[.006, .015]$} \\
Wine knowledge (1 to 10) & $.087 * * *$ & .124 & .056 & {$[-.158, .333]$} \\
(Constant) & -.810 & 1.672 & & \\
\hline
\end{tabular}

${ }^{*} p \leq .05, * * p \leq .01, * * * p \leq .001$

$$
\begin{gathered}
\mathrm{Y}=-.810+.025(\text { age })+-.337(\text { gender })+-.188(\text { income })+ \\
.219(\text { education })+1.050(\text { marital status })+-.353(\text { wine class })+ \\
.011(\$ \text { wine purchased monthly })+.087(\text { wine knowledge })
\end{gathered}
$$

For research question 2a, a general linear model (GLM), or flexible generalization of ordinary linear regression allowing for response variables that have other than a normal distribution, was used to determine the perceived social appropriateness of various closure types and how they differ according to social occasion. Regarding the perceived social appropriateness of different types of wine bottle closures for everyday drinking, the results show that there was a significant effect of wine closure method, $F(1.607,425.863)=25.286, p \leq .001$. 
Table 10: Results of GLM on Social Inappropriateness of Closure Type in Different Social Situations

Wine Bottle Closure Types

\begin{tabular}{lcccc}
\hline Social Situations & Natural Cork & Artificial Cork & Screw Cap & $F$ \\
\hline & Mean (SD) & Mean (SD) & Mean (SD) & \\
\hline Everyday drinking & $1.09(.282)$ & $1.19(.456)$ & $1.32(.633)$ & $25.286^{* * *}$ \\
Dinner party & $1.07(.252)$ & $1.29(.551)$ & $1.62(.804)$ & $77.013^{* * *}$ \\
Restaurant dinner & $1.07(.259)$ & $1.37(.627)$ & $1.80(.890)$ & $109.259^{* * *}$ \\
Large wine party & $1.12(.334)$ & $1.39(.655)$ & $1.72(.850)$ & $79.465^{* * *}$ \\
Large social function & $1.12(.356)$ & $1.27(.553)$ & $1.52(.759)$ & $49.531^{* * *}$ \\
\hline
\end{tabular}

${ }^{*} p \leq .05, * * p \leq .01, * * * p \leq .001$

As seen in Table 10, a series of follow-up comparisons were performed. These comparisons revealed that the differences in the means for perceived social appropriateness of each closure type were significantly different for each type of closure (e.g., the perceived appropriateness for natural cork differed from artificial cork, which differed from screw cap, etc.). The type of closure that was perceived as the most socially appropriate for drinking on a daily basis was natural cork (Mean=1.09), followed by artificial cork $(\mathrm{M}=1.19)$, and natural cork $(\mathrm{M}=1.32)$, where higher scores indicate increasing perceived social inappropriateness. 
The pattern was similarly observed in dinner party settings. The results show that there was a significant effect of wine closure method, $F(1.618,137.801)=77.013, p \leq$ .001. Comparisons revealed that the differences in the means for perceived social appropriateness of each closure type were significantly different for each type of closure, as with the previous model. The type of closure that was perceived as the least socially appropriate for drinking on in a dinner party setting was screw cap $(M=1.62)$, followed by artificial cork $(\mathrm{M}=1.29)$, and natural cork $(\mathrm{M}=1.07)$, where higher scores indicate increasing perceived social inappropriateness.

Regarding the perceived social appropriateness of different types of wine bottle closures for dinner in a restaurant, the results show that there was a significant effect of wine closure method, $F(1.697,446.403)=109.259, p \leq .001$. As with the other comparisons, the means for each type of closure were significantly different from one another. The type of closure that was perceived as the least socially appropriate for dinner at a restaurant was screw cap $(M=1.80)$, followed by artificial cork $(M=1.37)$, and natural $\operatorname{cork}(\mathrm{M}=1.07)$.

Regarding the perceived social appropriateness of different types of wine bottle closures for a large wine party, the results show that there was a significant effect of wine closure method, $F(1.765,465.914)=79.465, p \leq .001$. Just as seen above, the means for each type of closure were significantly different from one another. The type of closure that was perceived as the least socially appropriate for drinking on at a large party was screw cap $(\mathrm{M}=1.72)$, followed by artificial cork $(\mathrm{M}=1.39)$, and natural cork $(\mathrm{M}=1.12)$. 
Looking at the perceived social appropriateness of different types of wine bottle closures for a large social function, the results show that there was a significant effect of wine closure method, $F(1.565,413.244)=49.531, p \leq .001$. Additional comparison test showed the means for each type of closure were significantly different from one another. The type of closure that was perceived as the least socially appropriate for drinking during a large social function was screw cap $(\mathrm{M}=1.52)$, followed by artificial cork $(\mathrm{M}=1.27)$, and natural cork $(\mathrm{M}=1.12)$.

Summarized, the results yielded from the GLM model looking at natural cork, synthetic cork and screw cap wines compared across five different social situations including everyday drinking, a dinner party, a restaurant dinner, a large wine party and large social function were found to be significant at a $\mathrm{p} \leq .001$ level. In the following figure, one can observe the difference in means by closure type across all social situations. In Figure 13, it can be seen that screw cap closures were the most inappropriate closure type for every situation. Figure 13 gives a visual summary of the information from Table10. Screw caps are most inappropriate at a restaurant dinner $(\mathrm{M}=1.80)$, followed by a large wine party $(\mathrm{M}=1.72)$ and a dinner party $(\mathrm{M}=1.62)$. Screw cap overall were the most inappropriate, but respondents found them to be the least inappropriate for everyday drinking $(\mathrm{M}=1.32)$. 


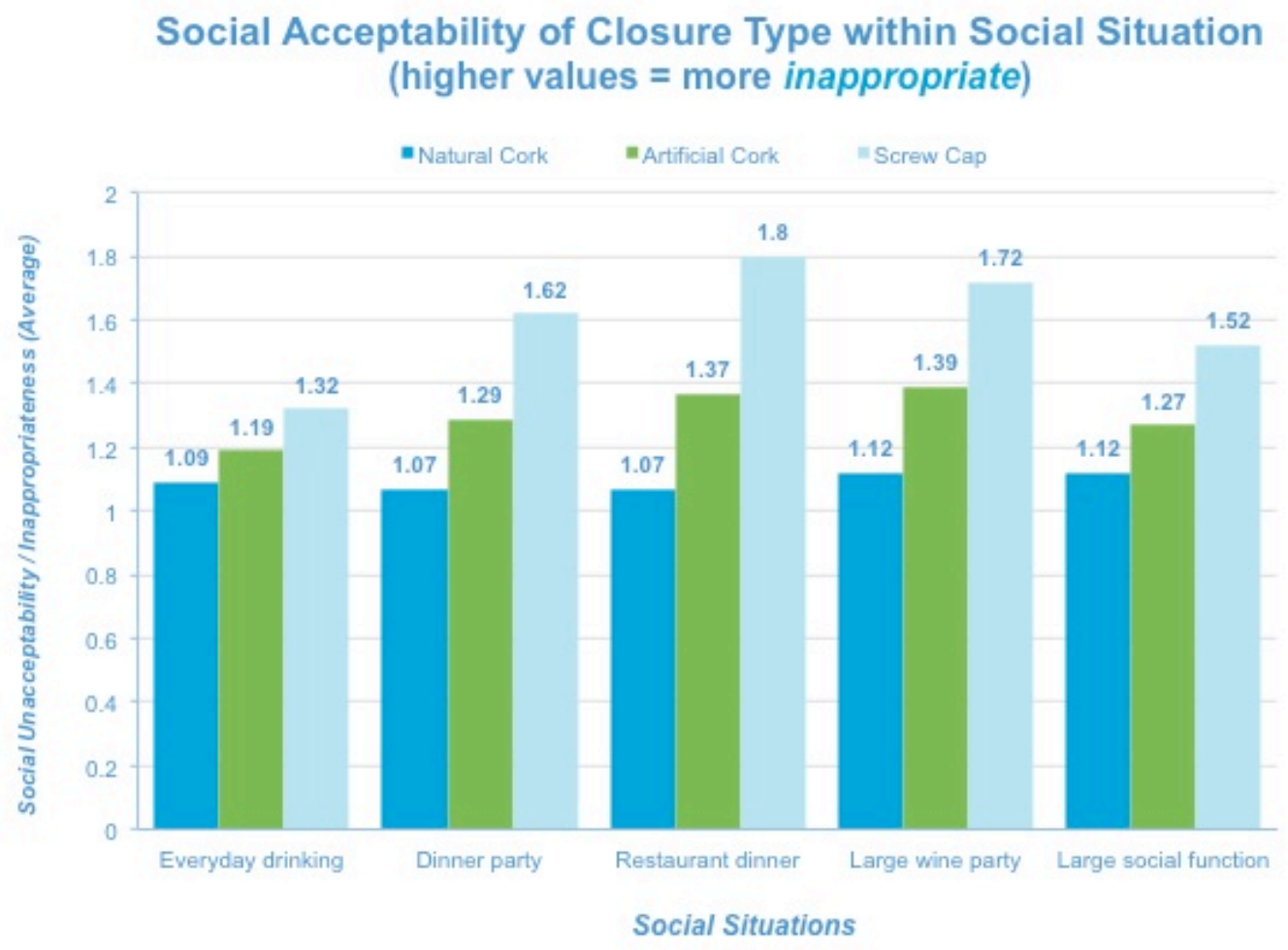

Figure 13: Social acceptability of Closure Type within Social Situation

For research question $2 \mathrm{~b}$, the likelihood of consumers bringing screw cap wines to specific social gatherings was evaluated using logistic regression (binary logit model). The logistic approach was chosen, largely because of the binary nature of the dependent variables, likelihood to purchase screw cap wines (likely or unlikely).

While looking at the case of the participants attending a party at their boss's home, several independent variables such as age, gender, income, education, marital status, wine classes taken, monthly wine expenditure and assessed wine knowledge were examined in regards to their influence on the respondent's likelihood to bring screw cap 
wine (not likely/likely). Age and education were both found to be significant at the $\mathrm{p} \leq .05$ level. As age increases, respondents are less likely to bring screw cap wine to the party of a boss $\left(b=-.028\right.$, Wald $\left.\chi^{2}(1)=5.824, p \leq .05\right)$. Education however has a positive effect, meaning that as a respondent's education increases, so does the likelihood that respondent will bring screw cap wine to a boss' party $\left(b=.383\right.$, Wald $\chi^{2}(1)=5.337, p \leq$ $.05)$. No other variables in this model were significant.

Table 11:Results Likelihood to Bring Screw Cap Wine to Boss Party

Binary Logit Model

\begin{tabular}{llcc}
\hline Variables & \multicolumn{1}{c}{$\beta$} & SE $\beta$ & $95 \%$ CI \\
\hline Age & $-.028^{*}$ & .012 & {$[.951, .995]$} \\
Gender (female) & -.507 & .300 & {$[.334,1.084]$} \\
Income & -.022 & .057 & {$[.874,1.094]$} \\
Education & $.383^{*}$ & .165 & {$[1.061,2.027]$} \\
Marital status (single) & .462 & .341 & {$[.813,3.098]$} \\
Wine class (yes) & -.049 & .332 & {$[.497,1.826]$} \\
Wine purchase monthly (\$) & -.001 & .001 & {$[.999,1.003]$} \\
Wine knowledge (1 to 10) & .069 & .073 & {$[.929,1.237]$} \\
(Constant) & -1.400 & .979 & \\
\hline
\end{tabular}

$* p \leq .05, * * p \leq .01, * * * p \leq .001$

$$
P(Y)=\frac{1}{\left.1+e^{+.462(\text { maritalstatus })+-.049(\text { wineclass })+-.001(\text { ( })+\text { wine })+.069(\text { wineknowle dge })}\right)}
$$

When examining the binary logit regression model ran collectively considering likelihood of bringing screw cap wine to dinner with a close friend, both age and education are significant. Age is significant at the $\mathrm{p} \leq .01$ level $\left(b=-.037\right.$, Wald $\chi^{2}(1)=$ 9.182, $\mathrm{p} \leq .01)$, while education is significant at the $\mathrm{p} \leq .05$ level $\left(\mathrm{b}=.319\right.$, Wald $\chi^{2}(1)=$ 4.147, $\mathrm{p} \leq .05)$. When looking at age, as a respondent gets older, they become less likely to bring screw cap wines to dinner with a close friend. Conversely, as a respondent's 
education becomes greater, they are significantly more likely to bring screw cap wines to a dinner with a close friend.

Table 12: Results Likelihood to Bring Screw Cap Wine to Dinner with Close Friends Binary Logit Model

\begin{tabular}{llcc}
\hline Variables & \multicolumn{1}{c}{$\beta$} & SE $\beta$ & $95 \%$ CI \\
\hline Age & $-.037^{* *}$ & .012 & {$[.941, .987]$} \\
Gender (female) & -.002 & .316 & {$[.537,1.854]$} \\
Income & .067 & .062 & {$[.947,1.207]$} \\
Education & $.319^{*}$ & .157 & {$[1.012,1.871]$} \\
Marital status (single) & -.121 & .368 & {$[.431,1.821]$} \\
Wine class (yes) & .555 & .370 & {$[.844,3.597]$} \\
Wine purchase monthly (\$) & .001 & .001 & {$[.998,1.004]$} \\
Wine knowledge (1 to 10) & .045 & .077 & {$[.899,1.217]$} \\
(Constant) & -.304 & .950 & \\
\hline
\end{tabular}

${ }^{*} p \leq .05, * * p \leq .01, * * * p \leq .001$

$$
P(Y)=\frac{1}{1+e^{+-.121(\text { maritalstatus })+.055(\text { wineclass })+.001(\text { ( } w \text { wine })+.045(\text { wineknowledge })}}
$$

In a similar binary logit regression model, independent variables of age, gender, income, education level, marital status, wine classes taken, monthly wine expenditures and assessed wine knowledge and dependent variable, likelihood to bring screw cap wine to a Christmas party were examined. Run in this model, age is significant at the $\mathrm{p} \leq .01$ level $\left(b=-.034\right.$, Wald $\left.\chi^{2}(1)=7.911, p \leq .01\right)$. This shows that as respondents get older, again, they become less likely to bring screw cap wines to a Christmas party.

Additionally, education significantly affects likelihood of bringing screw cap wines to a Christmas party positively at a $\mathrm{p} \leq .01$ level $\left(\mathrm{b}=.489\right.$, Wald $\chi^{2}(1)=8.865, \mathrm{p} \leq$ $.01)$. As respondent's level of education increases, so does the likelihood they will bring 
screw cap wines to a Christmas party. Gender was significant at a $p \leq .05$ level $(b=-.697$, Wald $\left.\chi^{2}(1)=4.560, p \leq .05\right)$, signifying that males were more likely to bring screw cap wines to a Christmas party than females. There were no significant findings regarding income, marital status, wine classes taken, monthly wine expenditures and wine knowledge and likelihood to bring screw cap wines to a Christmas party.

Table 13: Results Likelihood to Bring Screw Cap Wine to Christmas Party

Binary Logit Model

\begin{tabular}{llcc}
\hline Variables & \multicolumn{1}{c}{$B$} & SE $\beta$ & $95 \%$ CI \\
\hline Age & $-.034^{* *}$ & .012 & {$[.943, .990]$} \\
Gender (female) & $-.697^{*}$ & .326 & {$[.263, .944]$} \\
Income & .005 & .063 & {$[.888,1.137]$} \\
Education & $.489^{* *}$ & .164 & {$[1.182,2.249]$} \\
Marital status (single) & -.403 & .375 & {$[.321,1.393]$} \\
Wine class (yes) & .252 & .373 & {$[.620,2.671]$} \\
Wine purchase monthly $(\$)$ & .001 & .001 & {$[.998,1.003]$} \\
Wine knowledge (1 to 10) & .066 & .080 & {$[.914,1.249]$} \\
(Constant) & -.290 & .987 & \\
\hline
\end{tabular}

${ }^{*} p \leq .05, * * p \leq .01, * * * p \leq .001$

$$
P(Y)=\frac{1}{1+e^{+-.403(\text { maritalstatus })+.252(\text { wineclass })+.001(\text { ( } w \text { wine })+.066(\text { wineknowledge })}}
$$

An additional binary logit model was used to evaluate these independent variables on likelihood of bringing screw cap wine to a Thanksgiving dinner. When evaluated, the only significant variable turned out to be age $\left(b=.-.031\right.$, Wald $\left.\chi^{2}(1)=7.082, p \leq .01\right)$, which was significant at the $\mathrm{p} \leq .01$ level. This means, that as respondent age increases, the likelihood of them bringing a screw cap wine to Thanksgiving dinner decreases.

Table 14:Results Likelihood to Bring Screw Cap Wine to Thanksgiving Dinner

Binary Logit Model

\begin{tabular}{llcc}
\hline Variables & \multicolumn{1}{c}{$\beta$} & SE $\beta$ & $95 \%$ CI \\
\hline Age & $-.031^{* *}$ & .012 & {$[.947, .992]$} \\
Gender (female) & -.534 & .310 & {$[.319,1.076]$}
\end{tabular}




\begin{tabular}{llll} 
Income & .084 & .060 & {$[.968,1.223]$} \\
Education & .280 & .154 & {$[.979,1.790]$} \\
Marital status (single) & -.146 & .358 & {$[.428,1.744]$} \\
Wine class (yes) & .107 & .352 & {$[.558,2.220]$} \\
Wine purchase monthly $(\$)$ & .000 & .001 & {$[.997,1.002]$} \\
Wine knowledge (1 to 10) & .070 & .076 & {$[.924,1.245]$} \\
(Constant) & -.266 & .935 & \\
\hline
\end{tabular}

${ }^{*} p \leq .05, * * p \leq .01, * * * p \leq .001$

$$
P(Y)=\frac{1}{1+e^{+-.-146(\text { maritallatatus })+.107(\text { wineclass })+.000(\text { (Swine })+.070(\text { winekhowledge })}}
$$

When looking at the likelihood of bringing screw cap wine to a Superbowl party, independent variables such as age, gender, income, level of education, marital status, wine classes taken and wine knowledge were assessed using a binary logit regression model. Age was very significant at a $p \leq .01$ level $\left(b=. . .039\right.$, Wald $\chi^{2}(1)=9.299, p \leq$ $.01)$. This demonstrated that as respondent age increased, they were less likely to bring screw cap wines to a Superbowl party. Additionally, education was significant at a $\mathrm{p} \leq .05$ level $\left(b=.328\right.$, Wald $\left.\chi^{2}(1)=4.102, p \leq .05\right)$ and showed that as respondent's education level increased, they were more likely to bring screw cap wine to a Superbowl party. No other variables were significant in this model. 
Table 15:Results Likelihood to Bring Screw Cap Wine to a Superbowl Party

Binary Logit Model

\begin{tabular}{llcc}
\hline Variables & \multicolumn{1}{c}{$\beta$} & SE $\beta$ & $95 \%$ CI \\
\hline Age & $-.039^{* *}$ & .013 & {$[.938, .986]$} \\
Gender (female) & .126 & .334 & {$[.589,2.184]$} \\
Income & .113 & .066 & {$[.984,1.273]$} \\
Education & $.328^{*}$ & .162 & {$[1.011,1.907]$} \\
Marital status (single) & -.110 & .392 & {$[.415,1.933]$} \\
Wine class (yes) & .277 & .395 & {$[.608,2.862]$} \\
Wine purchase monthly (\$) & -.001 & .001 & {$[.997,1.002]$} \\
Wine knowledge (1 to 10) & .109 & .084 & {$[.946,1.315]$} \\
(Constant) & -.401 & .979 & \\
\hline
\end{tabular}

$* p \leq .05, * * p \leq .01, * * * p \leq .001$

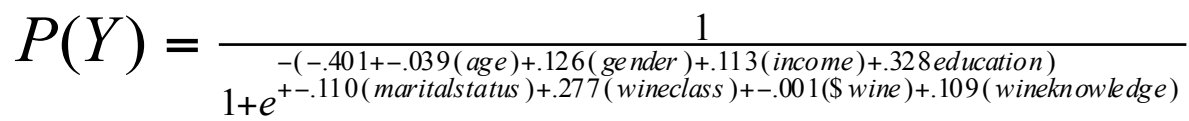

Examining the relationship between likelihood of bringing screw cap wine to a friend as a gift and multiple independent variables using the binary logit model yielded several significant findings. Age was found to be very significant at a $p \leq .001$ level $(b=-$ .045 , Wald $\left.\chi^{2}(1)=13.504, \mathrm{p} \leq .001\right)$. As respondents' get older, they are less likely to give screw cap wine as a gift to a friend. Income was significant at a $\mathrm{p} \leq .05$ level $(\mathrm{b}=-$ .004 , Wald $\left.\chi^{2}(1)=5.160, p \leq .05\right)$. As a respondent's income increases, they were less likely to gift screw cap wine to a friend. Education was also significant at a $\mathrm{p} \leq .05$ level $\left(b=.349\right.$, Wald $\left.\chi^{2}(1)=4.410, p \leq .05\right)$. As a respondent's education level increased, they were more likely to gift screw cap wine to a friend. 
Table 16:Results Likelihood to Bring Screw Cap Wine as a Gift for a Friend

Binary Logit Model

\begin{tabular}{llcc}
\hline Variables & \multicolumn{1}{c}{$\beta$} & SE $\beta$ & $95 \%$ CI \\
\hline Age & $-.045^{* * *}$ & .012 & {$[.933, .979]$} \\
Gender (female) & -.696 & .307 & {$[.273, .909]$} \\
Income & $-.004^{*}$ & .059 & {$[.887,1.118]$} \\
Education & $.349^{*}$ & .166 & {$[1.024,1.965]$} \\
Marital status (single) & .440 & .349 & {$[.783,3.078]$} \\
Wine class (yes) & .468 & .338 & {$[.823,3.100]$} \\
Wine purchase monthly (\$) & .001 & .001 & {$[.999,1.004]$} \\
Wine knowledge (1 to 10) & -.021 & .074 & {$[.848,1.132]$} \\
(Constant) & .016 & .971 & \\
\hline
\end{tabular}

$* p \leq .05, * * p \leq .01, * * * p \leq .001$

$$
P(Y)=\frac{1}{1+e^{+. .410(\text { maritalstatulus })+.468(\text { (wineclass })+.001(\text { (\$ wine })+-.021(\text { wineknowledge })}}
$$

\section{Results Summary}

For research question 1a, what factors influence decision to purchase screw cap wine, using the binary logit model, income was the only significant factor $(b=.246, \mathrm{p}<$ .01 ) when run alone. As a respondent's income increased, they became more likely to buy screw cap wines. Through a combined variable analysis conducted via binary logit regression, age was determined to be significant $(b=-.070, p<.01)$ and it was found that as a respondent gets older, they are less likely to purchase screw cap wines. Income was also found to be significant $(b=.242, p<.05)$, meaning that as a respondent's income increased, they were more likely to purchase screw cap wines.

When reviewing research question $1 \mathrm{~b}$, examining factors affecting number of screw cap wines bottles purchased per month, individual OLS models ran including age, 
income, wine knowledge yielded age significant $(b=.053, p<.001)$. In this case, as age increases, the number of bottle of screw cap wines purchased increases. Gender when ran through a one-sample t-test, was found to be significant $(\mathrm{p}<.001)$. The average number of screw cap bottles purchased was higher for males $(\mathrm{M}=2.68)$ than for females $(M=1.53)$. Lastly, income was found to be significant $(b=.198, p<.05)$, when evaluating the number of screw cap wine bottles purchased. As a respondent's income increases, so too did their likelihood to purchase screw cap wines.

Evaluating research question $2 \mathrm{a}$, looking at if screw cap, synthetic, and natural cork wine acceptance varies by social situation, there were significant differences. Screw cap wines were consistently viewed as most socially inappropriate wines in all social settings including everyday, etc. The difference in appropriateness between closure types was statistically significant at the $\mathrm{p} \leq .001$ level. Screw cap closures were the most inappropriate closure type for every social situation. Screw caps are most inappropriate in a restaurant setting $(\mathrm{M}=1.80)$.

Finally, results of research question $2 \mathrm{~b}$, which looked at the likelihood of bringing screw cap wines to various functions such as dinner at the house of a boss or a Christmas party, were found to include several significant factors across all social functions. Using a combined variable model (binary logit model), age was found to be significant $(b=-$ $.028, \mathrm{p}<.05)$ so as a respondent becomes older, they are less likely to bring screw cap wines to the house of a boss. Regarding likelihood of bringing screw cap wine to a boss' house, education was also significant $(b=.383, p<.05)$, meaning the higher a respondents 
education level, the more likely they were to bring screw cap wine to a boss' house. Across most social functions age and education remained significant. When looking at the likelihood of bring screw cap wines to a Christmas party, gender was significant ( $b=-$ $.697, \mathrm{p}<.05$ ) meaning women were less likely to bring screw cap wine to said Christmas party. When looking at the likelihood of bringing a screw cap wine as a gift, income was significant $(\mathrm{b}=-.004,<.05)$, meaning that the higher respondent income, the less likely they were to bring screw cap as a gift. 


\section{CHAPTER 5 DISCUSSION}

Introduction

This chapter will cover the study purpose, procedures, data analysis, delimitations, limitations, significant results and the study's research question. In addition to discussing relevant findings, the chapter will cover research implications and suggestions for future research.

\section{Summary of the Purpose}

The purpose of this study was to determine the factors that influence consumer purchase decisions regarding screw cap wines. Additionally, the study examined the variation of screw cap wine acceptance by social situation. Factors such as age, wine knowledge, income, education and gender were examined.

\section{Summary of Procedures}

For research question 1a, what factors influence decision to buy screw cap wine, individual and combined variable binary logit model and chi-squared analysis were used to evaluate the question. These tests were used specifically because the dependent variable, decision to purchase screw cap wines, was dichotomous in nature. In the case of the dependent variable, decision to purchase screw cap wines and independent variable, gender, chi-square was the appropriate statistical test needed.

The research question $1 \mathrm{~b}$, what factors influence number of screw cap bottles purchased by respondent, an Ordinary least squared regression (OLS) was performed in 
addition to a one-sample t-test. Since this data set contained a dependent variable that was continuous in nature (number of bottles of screw cap wine per month), the OLS procedure and t-test could easily be preformed.

When evaluating a model for research question $2 \mathrm{a}$, does wine closure type acceptance vary by social situation, several comparisons (closure types and social situations) were performed. A General linear model (GLM) was the most reasonable model due to the nominal nature of the variables (see appendix: planned analyses).

Lastly, research question $2 \mathrm{~b}$, do various factors impact the likelihood of respondent bringing screw cap wines to specific social events, was found using a binary logit regression model. This model was most appropriate because the dependent variable was looking at likelihood (yes/no) and thus, was dichotomous in nature.

All survey data was collected via Survey Monkey and exported to Excel. The data was then coded (and in some cases re-coded). This information was then sent to SPSS 20 were a number of tests were carried out based on addressing all aspects of the research questions above. 
Summary of Data Analysis

Data regarding respondents gender, income, marital status, age, education, wine course history, wine purchase history and wine knowledge were collected and analyzed in SPSS 20. A number of tests were performed on the data to test the research questions. This was done following the planned analyses document that is provided in the appendix. Such models included several binary logit regressions, a chi-square test, a one-sample ttest, Ordinary least squares model (OLS) and a General Linear Model (GLM).

\section{Delimitations}

The survey was available online from February 2, 2009 - March 16, 2009. Respondents were able to take the survey through links provided on Craigslist Los Angeles, Craigslist San Francisco and Craigslist San Diego. Invitations were also posted on a wine enthusiast page on Facebook. All respondent data collected was unique and verified via IP address information. The survey attracted a $66.7 \%$ response rate

\section{Limitations}

The study was limited to those who responded to the online web survey. Also, study was limited only to respondents who use the web or email technologies. The largest amount of respondents fell between the 21-30 age range. Respondents in their forties were also largely represented. The survey was administered in 2009 . This means, there could be discrepancies in consumer attitudes about screw cap closures since this data was not recently compiled. 


\section{Summary of Significant Findings}

For research question 1a, what factors influence decision to purchase screw cap wine, income was the only significant factor $(b=.246, \mathrm{p}<.01)$ when run alone using the binary logit model. As a respondent's income increased, they became more likely to buy screw cap wines. Through a combined variable analysis conducted via binary logit regression, age was determined to be significant $(b=-.070, p<.01)$ and it was found that as a respondent gets older, they are less likely to purchase screw cap wines. Income was also found to be significant $(b=.242, p<.05)$, meaning that as a respondent's income increased, they were more likely to purchase screw cap wines. Gender was not significant when evaluated via chi-square test.

Looking at number of bottles consumers purchased monthly, age was significant $(\mathrm{b}=.053, \mathrm{p}<.001)$. This was a positive relations whereby as a respondent ages, the number of screw cap wine purchased increases. As respondents' age increases, their likelihood of trying wine for the first time is not very good. But when they become wine drinkers, as they age, they purchase more wine. This was a bit surprising to learn, considering that age/decision to purchase screw cap wines (yes/no) relationship turned out to have a negative effect. Apparently, when making the decision to purchase screw cap wines for the first time, age negatively affects this decision. But as respondents purchase screw cap wine often, age increases the number of bottles they are willing to buy. This is a tricky observation because initially older people would not be an ideal market segment, but as they start buying screw cap wine, they are inclined to continue to buy more as they get older. 
Gender, when run through a one-sample t-test, was found to be significant $(\mathrm{p}<$ $.001)$. The average number of screw cap bottles purchased was higher for males $(\mathrm{M}=2.68)$ than for females $(\mathrm{M}=1.53)$. Males purchased more screw cap wines than females, so it might be worthwhile to target males via commercials on ESPN, for example. Income was also found to be significant $(b=.198, p<.05)$. Wealth has a positive relationship with numbers of screw cap bottles purchased. Wealthy people might be a good marketing segment to approach for screw cap wine marketing. Previous tests performed in this study have shared similar results regarding income.

When looking at acceptance of screw cap, synthetic and natural cork wines, results were statistically significant at the $\mathrm{p} \leq .001$ level, acknowledging that were different acceptance levels between all closure methods in every social situation presented. This further reinforces previous research showing that disparities between consumer acceptance of different closure type exists. Screw cap closures were the most inappropriate closure type for every social situation. One can see how there might be negative consumer perceptions based on this finding.

Age significantly $(b=-.028, p<.05)$ affected the likelihood of bringing screw cap wine to the home of a boss, negatively. Older people were less likely to bring wine to a boss' house. Perhaps experience in social situations is a benefit of age. This seems to indicate that negative perceptions of screw cap wines may be present and perhaps someone with more experience can navigate away from a potentially disastrous snafu: 
offending a boss with “cheap" wine. But as respondents' education level increased, they were significantly more likely $(b=.383, p<.05)$ to bring screw cap wine to a boss' house. Maybe experience dictates you avoid offending your boss, but education possibly allows you to mention a New York Times article about the benefits of screw cap wine closures and really impress your boss.

Age and education significantly maintained the above-mentioned relationships throughout most other social situations including: dinner with friends, a Christmas party and a Superbowl party. At a Christmas party, gender (coded female $y / n$ ) was significant $(b=-.697, p<.05)$, meaning women were less likely to bring screw cap wine to said Christmas party. One could consider that women are social creatures and that at one of the most important social events of the year, a woman might want her dress to turn heads, instead of her screw cap wine offering.

One significant finding was that income has a significantly negative relationship $(b=-.004, p<.05)$ with likelihood of gifting screw cap wine. Gifting screw cap wine seemed to be a unique social situation whereby the objective in most gifting settings is to impress the recipient. It might dull the wow affect to give someone a $\$ 90$ PlumpJack reserve cabernet sauvignon with a screw cap and then have your recipient shrug his or her shoulders at the gesture. One other interpretation is that there might be less availability on the market for expensive screw cap wine offerings and the recipient might as well receive additional perceived benefit of wine with a natural cork. Ninety percent of U.S. consumers, polled in a study, would not give a friend of the family a screw cap wine as a 
gift (R Bleibaum et al., 2005). Perceived disapproval by family and friends presents a social cost preventing the gifting, and hence purchasing, of screw cap wines, so this test finding aligns with previous research performed in the field.

\section{Practical Implications}

Since this study proved that factors such as age, wine knowledge, income and gender do influence screw cap wine purchase decisions and likelihood to bring given a variety of different social situations, the wine industry can focus on consumer segmentation of these factors to more effectively seek positive outcomes with consumer acceptance of screw cap wines.

One implication for the industry is that targeting high-income consumers will yield higher results than lower-income consumers. Additionally, seeking out consumers with high levels of education and focusing marketing efforts on them will be more effective than seeking less educations consumers. It was found that age has a negative

effect on screw cap wine acceptance in social situations such as a small dinner party. If it is known that the older the consumer gets, the less accepting of screw caps they are, then it would be prudent to focus marketing efforts on younger consumers, still willing to change behavioral habits to accept screw cap wines. One exception to this rule is when already purchasing screw cap wines, the older one gets, the more one buys.

Males seemed to find screw cap wines acceptable in more social situations than females. Using this insight, the industry could focus on men to target screw cap wines to, 
but perhaps use suggestive advertising to reinforce the social acceptance and usage of screw cap wines in social situations. Lastly, certain social situations seemed to enjoy more consumer acceptance of screw caps than others. Screw cap advertisements might be more effective if they featured people enjoying themselves at a Superbowl party with screw cap wines or conveniently opening a screw cap in a casual setting like everyday drinking at home.

In summary, this study has provided several insights into consumer acceptance of screw cap wines. Using the information provided in this study, the wine industry can narrow its target demographics and knowledge of behavioral acceptance in social situations to yield effective results regarding screw cap wine product offerings. Additional studies could also shed more insight onto why wine knowledge and higher income positively affects consumer acceptance of screw cap wines.

\section{Recommendation for future research}

One place to conduct future research is to determine why consumers accept screw caps less and more depending on different social situations. Research could be conducted to determine if age has effect on acceptance of screw cap wines in younger demographic pools. Additionally, a repeat survey could be launched to see if attitudes have changed since 2009 .

The more that is understood about consumer attitudes toward screw cap wines, the more consumer acceptance and adoption of screw cap wines will occur. In addition to this information, the United States wine industry needs to ban together to pool resources 
into a large scale effective marketing campaign, educating stakeholders and communicating screw cap value to the correct market segments. 


\section{REFERENCES}

Atkin, T., Garcia, R., \& Lockshin, L. (2006). A Multinational Study of the Diffusion of a Discontinuous Innovation. Australasian Marketing Journal (AMJ), Volume 14(2), 17-33. Retrieved from http://www.sciencedirect.com/science/article/pii/S1441358206700581 doi:10.1016/S1441-3582(06)70058-1.

Barber, N., Almanza, B., \& Donovan, J. (2006). Motivational Factors of gender, income and age on selecting a bottle of wine. International Journal of Wine Marketing, $18(3), 218-232$.

Bleibaum, R. (2011). Update : Consumer Attitudes of Wine Closures. 1-17. Retrieved from http://www.tragon.com/downloads/news/18.pdf

Bleibaum, R., Lattey, K. A., \& Francis, I. L. (2005). Conjoint research for consumer perception of wine closure options and their impact on purchase interest in the United States and Australia Tragon Corporation \& AWRI (pp. 38). Davis, CA: Tragon Corporation \& UC Davis Extension.

Charters, S., \& Pettigrew, S. (2006). I like it but how do I know if it's any good? Quality and preference in wine consumption, from http://ro.ecu.edu.au/ecuworks/3200

Choi, P., Garcia, R., \& Friedrich, C. (2010). The drivers for collective horizontal coopetition: a case study of screwcap initiatives in the international wine industry. International Journal of Strategic Business Alliances, 1, 271-290. Retrieved from http://inderscience.metapress.com/content/71h8379t44283366/fulltext.pdf doi:10.1504/ijsba.2010.030427 
Garcia, R., Bardhi, F., \& Friedrich, C. (2011). Overcoming Consumer Resistance to Innovation. MIT Sloan Management Review, 48(48419), 82-88.

Garcia, R., Rummel, P., \& Hauser, J. (2007). Validating agent-based marketing models through conjoint analysis (Vol. 60, pp. 848-857). Massachusetts Institute of Technology, United States: Journal of Business Research.

Gardner, D. (2008). Innovative Packaging for the Wine Industry: A Look at Wine Closures: Virginia Tech.

Goode, J. (2007). Reductive Reasoning: Getting to the bottom of 'reduction' problems in screwcaps Wines \& Vines (Vol. 88, pp. 22-30).

Longo, D. (2005, Oct 15, 2005). Drink up. Progressive Grocer: New York, 84, 52-57.

Marin, A. B., \& Durham, C. A. (2007). Effects of Wine Bottle Closure Type on Consumer Purchase Intent and Price Expectation. American Journal of Enology and Viticulture, 58, 192-201. Retrieved from http://ajevonline.org/content/58/2/192.full.pdf + html

Orth, U. R., Wolf, M. M., \& Dodd, T. H. (2005). Dimensions of wine region equity and their impact on consumer preferences. Journal of Product \& Brand Management, 14(2), 88-97. Retrieved from http://www.emeraldinsight.com/journals.htm?issn=1061$\underline{0421 \& \text { volume }=14 \& \text { issue }=2 \& \text { articleid }=1464143 \& \text { articletitle }=\text { Dimensions }+ \text { of }+ \text { win }}$ $\underline{\text { e}+ \text { region }+ \text { equity }+ \text { and }+ \text { their }+ \text { impact }+ \text { on }+ \text { consumer }+ \text { preferences }}$ doi:http://dx.doi.org/10.1108/10610420510592563

Phillips, C. (2011). 2011 Closure Survey Report: Wine Business Monthly. 
Ritchie, C. (2007). Beyond drinking: the role of wine in the life of the UK consumer. International Journal of Consumer Studies, 31(5), 534-540.

Speedy, B. (2010). Screwcaps give better sense of closure: The Australian.

Tinney, M.-C. (2007). Retail Sales Analysis: Screw Caps Flummox Wine Industry. Wine Business Monthly.

Wilson, D., \& Lockshin, L. (2003). The Communications Issues for Producers of Alternative Closures in the Wine Industry. International Colloquium in Wine Marketing, pp. 1-18. Retrieved from http://academyofwinebusiness.com/wpcontent/uploads/2010/05/File-020.pdf 
APPENDIX: SURVEY, PLANNED ANALYSIS 


\section{Full Version Wine Closure Survey}

\section{Informed Consent Form}

1. A research project is being conducted by Lauren J eter, a graduate student in the Department of Agribusiness at Cal Poly - San Luis Obispo. The purpose of the study is to collect consumer information regarding wine closure (natural cork, synthetic cork, screw cap) preferences.

You are being asked to participate in this research by completing a survey that is estimated to take somewhere between 5 and 25 minutes. Please be aware that participation is voluntary and you may discontinue participation at any time without penalty. I $t$ is also acceptable to omit any questions you prefer not to answer.

There are no risks anticipated as a participant in this survey. Your participation will be anonymous unless you provide your contact information to the researcher for the sole purpose of verification of your responses. There are no direct benefits to you as a respondent to this survey. However, your participation will further understanding of consumer preferences and attitudes about wine closure options.

If you have questions about this survey or would like to obtain the results once the study has been completed, please contact Lauren Jeter at (805) 215-8212, ljeter@calpoly.edu. If you have concerns regarding the manner in which this research has been conducted, please be aware that you may contact Dr. Susan Opava, Dean of Research and Graduate Programs, at (805) 756-1508, sopava@calpoly.edu.

Please print out a copy of this informed consent form NOW for your reference.

If you agree to voluntarily participate in this research project as described, please indicate your agreement by continuing on to complete the survey.

Thank you for your participation in this research.

$\bigcirc$ Yes, I'd like to participate

No, I decline to participate

2. Wine Purchase History

2. Do you drink wine?

$\bigcirc$ No

Y Yes 


\section{Full Version Wine Closure Survey}

3. Which of the following alcoholic beverages have you or a member of your family consumed during the past year? (Check all that apply)

Other

Sparkling Wine

Mixed Drinks

Wine

Beer

4. How many bottles of wine do you typically purchase per month?

Red Wine

White Wine

Sparkling Wine

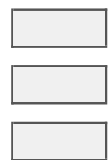

5. How many bottles of each choice did you purchase last month?

Natural Cork Wine

Artificial Cork Wine

Screw Cap Wine

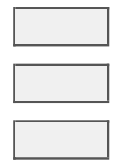

6. Of screw cap wine purchases, which type of wine do you purchase most frequently?

Red wine

White wine

Do not purchase screw cap wine

7. How much money do you typically spend on wine in a month?

Red wine \$

White wine

8. Of wine purchased last month for consumption at home, how many bottles fell into the following price ranges?

Bottles Purchased

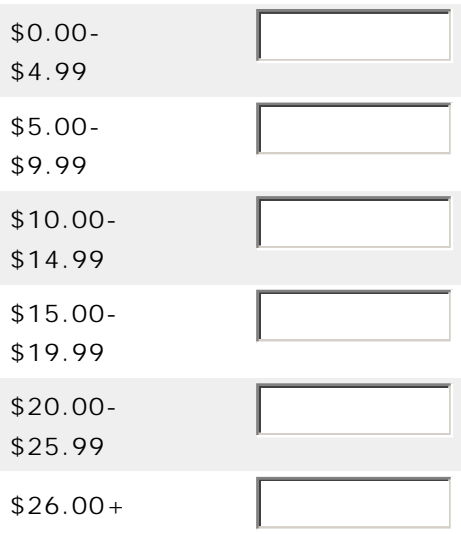




\section{Full Version Wine Closure Survey}

9. Of screw cap wines purchased for home consumption during the past month, how many bottles fell into the following price ranges?

Bottles Purchased

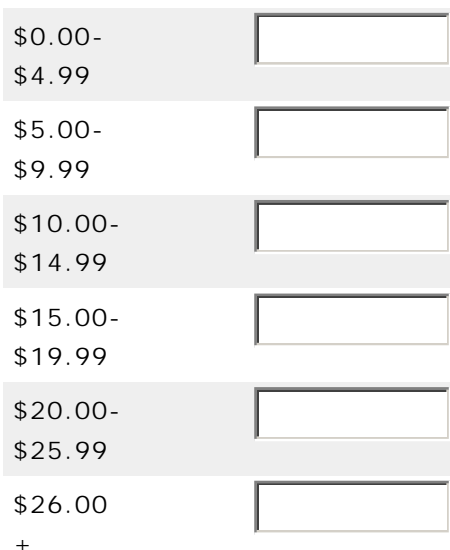

10. Which of the following is your primary source of wines purchased for home consumption?

$\bigcirc$ Wine Specialty shop

Grocery Store

Liquor Store

$\bigcirc$ winery

Wholesale Discount Store

$\bigcirc$ Wine Club

Other (please specify)

\section{Demographics}

11. Which best describes your marital status?

Married

single

Separated

Other ( please specify)

12. Which best describes your gender?

Male

Female

13. Please enter your age in years, in the box below. 


\section{Full Version Wine Closure Survey}

14. How many children do you have, under 18, living in your home?

15. Which best describes your highest level of formal education?

Grade school or less

Some High School

High School Graduate

Some college

College Graduate

Post-Graduate Work

16. Have you ever taken any courses in wine appreciation?

$\bigcirc$ No

PYes

17. Which best describes your current employment status?

Employed, Full-time

Employed, Part-time

$\bigcirc$ stay at home Parent

$\bigcirc$ Not employed

$\bigcirc$ Retired

Other

18. Which best describes your annual household income?

Dollars

Annual Income

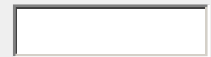

19. Are you a member of a Wine Club?

$\bigcirc$ No

PYes

20. If you answered yes to the previous question, does your wine club offer any screw cap wines?

$\bigcirc$ No

$\bigcirc$ Yes

I 'm not a member of a wine club 


\section{Full Version Wine Closure Survey}

\section{Please choose your level of agreement for the following statements.}

I would buy wine with a
synthetic cork
I would buy wine with
natural cork
I would buy wine with a
screw cap
I believe that wines with
synthetic corks are
higher in quality than
those of natural cork
I believe that wines with
screw caps are higher in
quality than those of
natural cork
I would be disappointed
if I bought a wine at a
restaurant and it came
with a synthetic cork
I would be disappointed
if I bought a wine at a
restaurant and it came
with a screw cap
In a restaurant, I would
send back a wine that
came with a synthetic
cork
In a restaurant, I would
send back a wine that
came with a screw cap

Agree

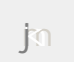

$\bigcirc$

$\bigcirc$

$\bigcirc$

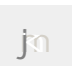

$\bigcirc$

Disagree

$\bigcirc$

0

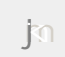

0

0

0

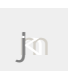

0

0

0

0

22. Rate your personal wine knowledge on a scale of 1-10, with 1 being little to no knowledge and 10 being a great deal of wine knowledge.
Wine Knowledge (Rate 1-
1
2
3
$\bigcirc^{4}$
$\stackrel{5}{\bigcirc}$

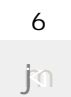
${ }^{7}$
$\stackrel{8}{\bigcirc}$
$\stackrel{9}{\bigcirc}$
10

23. Please rate your feelings of the social appropriateness of wine closure methods for each of the following situations.

Everyday drinking (1-2 people)
Dinner Party (2-4 people)
Restaurant Dinner (2-4 people)
Large wine party (8-12 people)
Large social function (20+ people)




\section{Full Version Wine Closure Survey}

24. Please rate your likeliness of bringing a screw cap wine to the following social functions:

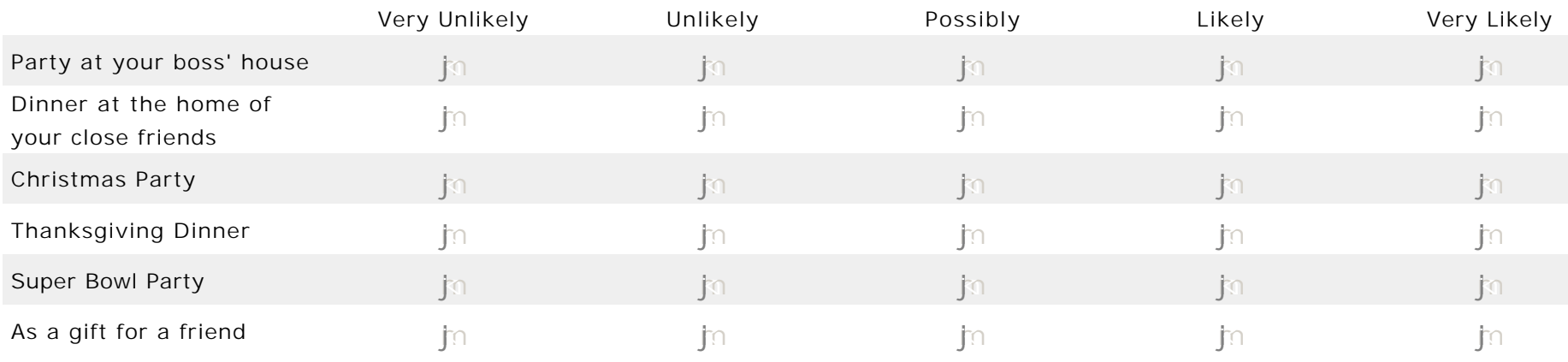

Please read the following scenario and answer Questions 21-26:

You are invited to a small social gathering at a friend's house. The host has only natural cork wines at the party. An invitee brings a screw cap wine to the party.

\section{Please rate your opinion for each of the following:}

The invitee is:

Frugal
Very knowledgeable about
wine
Modern
Educated
Probably a good friend of
the host
A wine enthusiast
Socially inappropriate

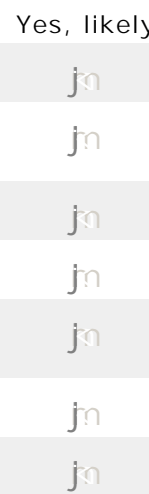

26. Disregarding quality and price of wine, based on scenario alone, rate invitee's wine knowledge on a scale of 1-10, with 1 being little to no knowledge and 10 being a great deal of wine knowledge.
Invitee Wine Knowledge
(Rate 1-10)
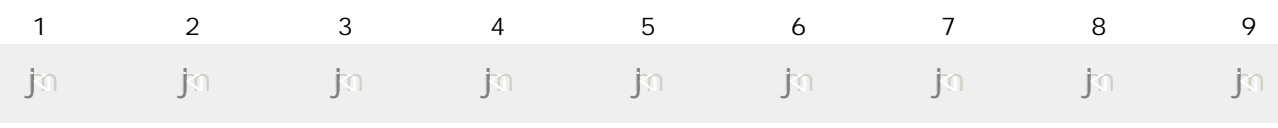

\section{Please estimate the invitee's level of education.}

Grade school or less

Some High School

High School Graduate

Some college

College Graduate

$\bigcirc$ Post-Graduate Work 


\section{Full Version Wine Closure Survey}

\section{Please estimate the approximate income level of the invitee}

$\bigcirc$ Less than $\$ 20,000$

○21,000-\$30,000

$\bigcirc \$ 31,000-\$ 40,000$

$\$ 41,000-\$ 50,000$

$\$ 51,000-\$ 60,000$

$\bigcirc \$ 1,000-\$ 70,000$

$\$ 71,000-\$ 80,000$

○81,000-\$90,000

$\$ 91,000-\$ 100,000$

$\$ 100,000+$

29. Based on scenario, would you invite this individual to a similar gathering hosted by yourself?

Not likely

$\bigcirc$ Yes, Likely

\section{Survey Completed}

Your survey is completed. Thank you for your time. 
RESEARCH QUESTIONS / HYPOTHESES (PLANNED ANALYSES - TEST STATISTICS)

\section{WHAT FACTORS INFLUENCE SCREW CAP WINE PURCHASES?}

\begin{tabular}{|c|c|c|c|c|c|}
\hline Outcome (DV) & Variables (item) & Type & By "Factors" (IVs) & Type & Statistic \\
\hline \multirow{5}{*}{$\begin{array}{l}\text { Purchase SC } \\
\text { (yes / no) }\end{array}$} & Purchase SC (yes / no) & $\begin{array}{l}\text { Nominal } \\
\text { (dichotomous) }\end{array}$ & Age & Interval & Logistic regression (binary logit mode \\
\hline & Purchase SC (yes / no) & $\begin{array}{l}\text { Nominal } \\
\text { (dichotomous) }\end{array}$ & Gender & Nominal & Chi squared non-parametric \\
\hline & Purchase SC (yes / no) & $\begin{array}{l}\text { Nominal } \\
\text { (dichotomous) }\end{array}$ & Income & Interval & Logistic regression (binary logit mode \\
\hline & Purchase SC (yes / no) & $\begin{array}{l}\text { Nominal } \\
\text { (dichotomous) }\end{array}$ & Wine Knowledge & Interval & Logistic regression (binary logit mode \\
\hline & Purchase SC (yes / no) & $\begin{array}{l}\text { Nominal } \\
\text { (dichotomous) }\end{array}$ & $\begin{array}{l}\text { Age, Gender, Income, Education, Marital status } \\
\text { Wine Class, \$ Wine per month, Wine Knowledge }\end{array}$ & Interval, Nominal & Logistic regression (binary logit mode \\
\hline \multirow{5}{*}{$\begin{array}{l}\text { \# Bottles SC } \\
\text { Purchased per } \\
\text { month }\end{array}$} & $\begin{array}{l}\text { \# Bottles SC purchase } \\
\text { per month }\end{array}$ & Ratio & Age & Interval & $\begin{array}{l}\text { Ordinary Least Squares (OLS) } \\
\text { Regression (continuous outcome) }\end{array}$ \\
\hline & $\begin{array}{l}\text { \# Bottles SC purchase } \\
\text { per month }\end{array}$ & Ratio & Gender & Nominal & T-test (independent samples) linear \\
\hline & $\begin{array}{l}\text { \# Bottles SC purchase } \\
\text { per month }\end{array}$ & Ratio & Income & Interval & $\begin{array}{l}\text { Ordinary Least Squares (OLS) linear } \\
\text { Regression (continuous outcome) }\end{array}$ \\
\hline & $\begin{array}{l}\text { \# Bottles SC purchase } \\
\text { per month }\end{array}$ & Ratio & Wine Knowledge & Interval & $\begin{array}{l}\text { Ordinary Least Squares (OLS) } \\
\text { Regression (continuous outcome) }\end{array}$ \\
\hline & $\begin{array}{l}\text { \# Bottles SC purchase } \\
\text { per month }\end{array}$ & Ratio & $\begin{array}{l}\text { Age, Gender, Income, Education, Marital status } \\
\text { Wine Class, \$ Wine per month, Wine Knowledge }\end{array}$ & Interval, Nominal & $\begin{array}{l}\text { Ordinary Least Squares (OLS) } \\
\text { Regression (continuous outcome) }\end{array}$ \\
\hline \multicolumn{6}{|c|}{ DOES SCREW CAP WINE ACCEPTANCE VARY BY SOCIAL SITUATION? } \\
\hline Outcome (DV) & Variables (item) & Type & By "Factors" (IVs) & Type & Statistic \\
\hline $\begin{array}{l}\text { Perceived Social } \\
\text { Appropriateness }\end{array}$ & $\begin{array}{l}\text { Natural Cork } \\
\text { Authentic Cork } \\
\text { Screw Cap }\end{array}$ & Nominal & $\begin{array}{l}\text { Level of appropriateness (1-3) } \\
\text { (Social Situations: Everyday drinking, Dinner party, } \\
\text { Restaurant, Large wine party, Large function) }\end{array}$ & Interval & General linear model (GLM) linear \\
\hline \multirow{5}{*}{$\begin{array}{l}\text { Likelihood to } \\
\text { bring Screw Cap } \\
\text { wine to specific } \\
\text { social events }\end{array}$} & Boss house & $\begin{array}{l}\text { Nominal } \\
\text { (dichotomous) }\end{array}$ & $\begin{array}{l}\text { Age, Gender, Income, Education, Marital status } \\
\text { Wine Class, \$ Wine per month, Wine Knowledge }\end{array}$ & Interval, Nominal & $\begin{array}{l}\text { Logistic regression (binary logit mode } \\
\text { probability }\end{array}$ \\
\hline & Dinner Close friends & $\begin{array}{l}\text { Nominal } \\
\text { (dichotomous) }\end{array}$ & $\begin{array}{l}\text { Age, Gender, Income, Education, Marital status } \\
\text { Wine Class, \$ Wine per month, Wine Knowledge }\end{array}$ & Interval, Nominal & Logistic regression (binary logit mode \\
\hline & Christmas party & $\begin{array}{l}\text { Nominal } \\
\text { (dichotomous) }\end{array}$ & $\begin{array}{l}\text { Age, Gender, Income, Education, Marital status } \\
\text { Wine Class, \$ Wine per month, Wine Knowledge }\end{array}$ & Interval, Nominal & Logistic regression (binary logit mode \\
\hline & Super bowl party & $\begin{array}{l}\text { Nominal } \\
\text { (dichotomous) }\end{array}$ & $\begin{array}{l}\text { Age, Gender, Income, Education, Marital status } \\
\text { Wine Class, \$ Wine per month, Wine Knowledge }\end{array}$ & Interval, Nominal & Logistic regression (binary logit mode \\
\hline & Gift for friend & $\begin{array}{l}\text { Nominal } \\
\text { (dichotomous) }\end{array}$ & $\begin{array}{l}\text { Age, Gender, Income, Education, Marital status } \\
\text { Wine Class, \$ Wine per month, Wine Knowledge }\end{array}$ & Interval, Nominal & Logistic regression (binary logit mode \\
\hline
\end{tabular}


SAMPLE STATISTICS

\begin{tabular}{|c|c|c|c|}
\hline Variable & Description & Type & Statistic \\
\hline Marital status & Married, Single, Separated, Other & Nominal & N, Percent, Mode \\
\hline Gender & Male (1), Female (2) & Nominal & $\mathrm{N}$, Percent \\
\hline Age & In years & Interval & N, Mean, Mode, Standard deviation, Standard Error of the Mean \\
\hline $\begin{array}{l}\text { Number of children } \\
\text { in household }\end{array}$ & Count (number) & Ratio & N, Mean, Mode, Standard deviation, Standard Error of the Mean \\
\hline Level of education & $\begin{array}{l}\text { Grade school, some high school, high } \\
\text { school, some college, college, post- } \\
\text { graduate }\end{array}$ & $\begin{array}{l}\text { Nominal } \\
\text { (categories) }\end{array}$ & N, Percent, Mode \\
\hline Income & Annual household income & Interval & N, Mean, Mode, Standard deviation, Standard Error of the Mean \\
\hline Wine club membership & No, Yes & Nominal & $\mathrm{N}$, Percent \\
\hline Wine club offer screw cap wines & No, Yes, Not a member & Nominal & N, Percent, Mode \\
\hline \multicolumn{4}{|c|}{ CONSUMER BEHAVIOR SUMMARY } \\
\hline Variable & Description & Type & Statistic \\
\hline Respondent consumes wine & No, Yes & Nominal & N, Percent \\
\hline $\begin{array}{l}\text { Types of screw cap wine } \\
\text { purchased most frequently }\end{array}$ & $\begin{array}{l}\text { Red, White, Do not purchase SC } \\
\text { Count (number) }\end{array}$ & Interval & N, Mean, Mode, Standard deviation, Standard Error of the Mean \\
\hline $\begin{array}{l}\text { Screw cap wine } \\
\text { bottles purchased last month }\end{array}$ & Count / number & Interval & N, Mean, Mode, Standard deviation, Standard Error of the Mean \\
\hline Amount spent on wine per month & Dollar amount & Interval & N, Mean, Mode, Standard deviation, Standard Error of the Mean \\
\hline $\begin{array}{l}\text { Bottles purchased last month } \\
\text { (by price category) }\end{array}$ & $\begin{array}{l}0-4.99,5-9.99 \\
10-14.99,15-19.99 \\
20-25.99,26+ \\
\text { (count / number) }\end{array}$ & Interval & N, Mean, Mode, Standard deviation, Standard Error of the Mean \\
\hline $\begin{array}{l}\text { Screw cap wine bottles } \\
\text { purchased last month } \\
\text { (by price category) }\end{array}$ & $\begin{array}{l}0-4.99,5-9.99 \\
10-14.99,15-19.99 \\
20-25.99,26+ \\
\text { (count / number) } \\
\end{array}$ & Interval & N, Mean, Mode, Standard deviation, Standard Error of the Mean \\
\hline Location of wine purchases & $\begin{array}{l}\text { Wine specialty shop, grocery store, liquor } \\
\text { store, winery, wholesale discount store, } \\
\text { wine club, other }\end{array}$ & $\begin{array}{l}\text { Nominal } \\
\text { (categories) }\end{array}$ & N, Percent, Mode \\
\hline
\end{tabular}

